\title{
Review Article \\ Recent Advances in Bidirectional Modeling and Structural Control
}

\author{
Satyam Paul, Wen Yu, and Xiaoou Li \\ Departamento de Control Automatico, CINVESTAV-IPN, 07360 Mexico City, DF, Mexico \\ Correspondence should be addressed to Wen Yu; yuw@ctrl.cinvestav.mx
}

Received 1 July 2015; Revised 22 September 2015; Accepted 29 September 2015

Academic Editor: Chia-Ming Chang

Copyright (C) 2016 Satyam Paul et al. This is an open access article distributed under the Creative Commons Attribution License, which permits unrestricted use, distribution, and reproduction in any medium, provided the original work is properly cited.

This paper provides an overview of building structure modeling and control under bidirectional seismic waves. It focuses on different types of bidirectional control devices, control strategies, and bidirectional sensors used in structural control systems. This paper also highlights the various issues like system identification techniques, the time-delay in the system, estimation of velocity and position from acceleration signals, and optimal placement of the sensors and control devices. The importance of control devices and its applications to minimize bidirectional vibrations has been illustrated. Finally, the applications of structural control systems in real buildings and their performance have been reviewed.

\section{Introduction}

Historic studies expose the fact that several earthquakes have caused severe damage in civil structures all over the world including 1985 Mexico City, 1994 Northridge, 1995 Kobe, 1999 Kocaeli, 2001 Bhuj, 2008 Sichuan, 2008 Chile, and 2012 Emilia. The process of modification or controlling the building structures from severe damage has became a salient topic in structural engineering. The control of building structures from the hazardous earthquake waves is an area of great interest for the researchers that is growing rapidly $[1,2]$. The challenging part of the job lies on the protection of super structures in the whole of geographic locations from the seismic events, thus providing a means of safer environment for the human occupants. The extensive damage due to an earthquake can be noteworthy and so there is utter necessity to develop an effective method for protection.

The structural control methodology and its applications during earthquakes were first suggested by the researches more than a century ago. But major developments have been noticed during the last 25 years where the structures with preventive systems have been developed. Yao in 1972 [3] had proposed the idea of structural control that played a major role in the advancement of the field of structural engineering.
In the area of structural design and its control, the following points should be taken care of:

(i) the pattern in which the ground vibrates during earthquake,

(ii) the design techniques of buildings to withstand earthquakes,

(iii) innovative strategies for the response control of building structures.

Passive and active control systems play an important role in the response reduction of civil engineering structures subjected to strong seismic vibrations. Passive, active, and semiactive control systems are the most important class of structural engineering. The two techniques that can be utilized for the control of structural vibrations are

(i) implementation of smart materials in the construction of buildings [4],

(ii) the use of control devices like actuators, dampers, and isolators in the building structures [5].

A worldwide popularity and high demand of structural control and its application had given rise to various researches leading to the publication of many textbooks, for example, 
[6]. The authors [4] had suggested different types of passive, active, semiactive, and hybrid control systems in their review paper that highlights the importance of control theory in the vibration control of structures. In this paper, a detailed review on various passive, semiactive, and hybrid control system applied to control the translation-torsion coupled response of structure under bidirectional seismic events are portrayed in sequential manner. Reference [1] had focused on in-depth studies about active, semiactive, and hybrid control devices along with some control strategies. The main factors affecting the performance of structural control can be categorized as

(i) excitation criteria (e.g., unidirectional or bidirectional earthquake and winds),

(ii) structural characteristics (e.g., natural frequency, degree-of-freedom, and nonlinearity in structures),

(iii) design of the control system (e.g., devices types and quantity, device placements, system models, and control algorithm) [7].

Although the most of research has been vested on the seismic analysis considering unidirectional seismic waves, very less researches have been detected on bidirectional seismic waves. The fact cannot be denied that the earthquake has indeed an arbitrary direction, represented by a bidirectional ground movement $[8,9]$. The bidirectional seismic inputs in buildings will induce translation-torsion coupled vibrations in buildings which are more severe with severe structural damage and should be taken into consideration [10]. The investigation revealed the fact that one of the prime factors of building collapse in recent times is asymmetric building structures under the grip of bidirectional seismic ground motions [11]. So a detailed review of a detailed methodology on selection of control criteria, mathematical modeling techniques, and the effectiveness of control device to protect the building structures from bidirectional seismic waves is required to be presented in potential manner.

The aim of this review is to address all aspects involved in bidirectional structure control, taking into consideration modeling and vibration control of building structures under bidirectional seismic inputs. This paper also addresses the application of all possible devices for bidirectional vibration control. The foundation on the methodology of state estimation, system identification, optimal device placement, and the effect of the time delay on the stability is discussed in this review. We compare different control strategies for the bidirectional vibrations, such as PID control, $H_{\infty}$ control, optimal control, sliding mode control, artificial neural network control, genetic control, and fuzzy control. The paper concludes with some of the observations noticed throughout the review.

\section{Bidirectional Modeling of Building Structures}

Structural mechanics involves the study of vibrations incorporated in structures. In order to control a structure effectively, it is important to have the knowledge about its dynamics. The control of structures is associated with the safeguard of building structures from unidirectional or bidirectional seismic forces. One of the structural design objects is to model dynamic loadings and to produce innovative approach to curb vibration. The vibration control generates the required dynamics in the building structures within a stable range. This control design is decided by the structure of mathematical model [12, 13]. In [4], a compact relationship between the controller and the structure model is established.

All engineering structures are composed of intrinsic mass and elastic characteristics. The dynamic modeling has similar characteristics with the static analysis. However, the dynamic analysis is much complex than static analysis. For example, the mass modeling technique for the dynamic model requires an elastic model and a mass model minutely refined by discrete masses [6].

2.1. Bidirectional Excitation. Recent earthquakes show that the bidirectional effect is the main damage source of the structural damage. The seismic analysis should consider the bidirectional excitation. The normal method of building structure design regards the seismic response arising from the ground motion that acts separately in the two orthogonal directions. Generally, the earthquake exhibits arbitrary direction which is represented as bidirectional ground movement, and it could reduce the participation of the traverse frames to the structure torsional and lateral stiffness. A noteworthy change in the elastic torsional behavior of the building is observed considering a nonlinear behavior in the transverse frames.

The effect of the magnitude of the axial forces acting in the corner columns in case of bidirectional ground motion subjected to structures is different from that in case of unidirectional ground motion [8]. Reference [14] also suggested that, for a structure exposed to two simultaneous horizontal earthquake components, the transverse element behavior can be nonlinear and so the contribution to the real torsional stiffness is smaller. Reference [15] presents the analysis of onestory models with and without transverse elements subjected to unidirectional and bidirectional earthquakes. The study concluded that the addition of the transverse elements in the model significantly hampers the response of the border elements when the structure is subjected to the bidirectional seismic waves.

The analysis of real buildings suggests that it is asymmetric in nature to some degree with a formal symmetric plan. The asymmetric nature of building will induce lateral as well as torsional vibrations simultaneously and is termed as torsion coupling (TC) considering the case of pure translational excitations. Soil-structure interaction (SSI) effects are considered and can be significant in case of the building structures constructed on soft medium. The effects of SSI can critically modify the dynamic characteristics of a structure such as natural frequencies, damping ratios, and mode shapes [16].

The knowledge of behavior and impact of the excitation forces plays a significant role in the formulation of the building structures dynamic model. The movement of the portion of the earth crust is termed as earthquake which is 

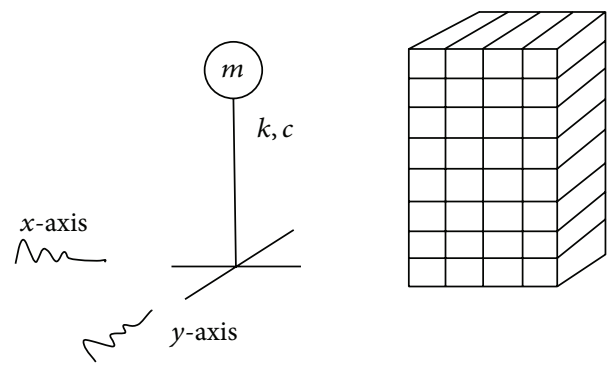

FIGURE 1: Bidirectional ground forces that are exerted on the building structures.

accompanied with the sudden release of stresses. Usually the epicenters for earthquake exist less than 25 miles below the earth's surface and are followed by series of vibrations. The bidirectional ground forces exerting on the building structure are shown in Figure 1. These forces result in series of structure vibrations.

The forces acting on the $x$-axis and $y$-axis can be illustrated by the following dynamic equations:

$$
\begin{aligned}
& f_{x}=-m \ddot{x}_{g}, \\
& f_{y}=-m \ddot{y}_{g},
\end{aligned}
$$

where $m$ is the mass and $\ddot{x}_{g}$ and $\ddot{y}_{g}$ are the ground accelerations, caused by the seismic waves.

The main factors of the seismic movement for the building are the amplitude (displacement, velocity, and acceleration) and the frequency of the ground motion. The ground motion is complex, and the vibration frequency is timevarying. The ground motion and the building vibration affect each other, depending on the distance between the natural frequency of the building structure and seismic motion frequency. When the seismic wave frequency is close to the natural frequency of the building, the damage becomes bigger. Structure analysis shows that the shorter the building, the higher the natural frequency. One of the prime concerns is controlling the structure vibrating with respect to low frequency, because the major part of the structure elastic energy is stored in low frequency zone [17].

2.2. Structure Model under Bidirectional Excitation. A controllable building structure can be regarded as a planar structure on a fixed base. The asymmetric characteristic of the building induces simultaneous lateral and torsional vibrations, known as torsion coupling (TC) [18], which are subjected to bidirectional seismic inputs. The schematic plan view of structure involving torsion coupled (TC) is shown in Figure 2. The impacts of seismic forces in $x$ and $y$ directions result in building oscillation as in Figure 3. In includes $x$ oscillation, $y$ oscillation, and the torsional oscillation defined as $\Phi$.

The simplest structure is one-story under lateral translational motion at the roof level. It is a single degree-of-freedom system. The motion model is [19]

$$
m \ddot{v}+c \dot{v}+k v=p(t),
$$

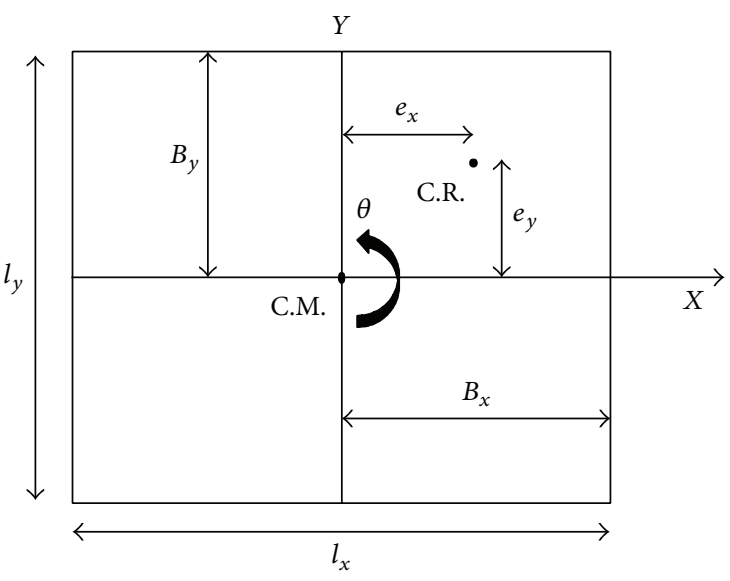

FIGURE 2: The torsion coupled force.

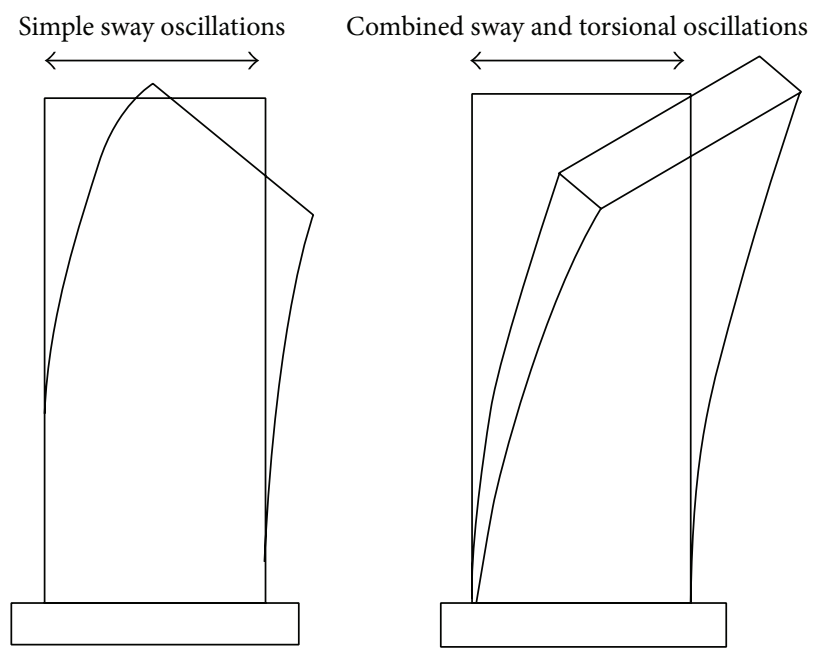

Figure 3: The seismic forces result in building oscillation.

where $m$ is the mass, $c$ is the damping, $k$ is the stiffness, $\ddot{v}$ is the acceleration of the mass, $\dot{v}$ is the velocity of the mass relative to the base, $v$ is the displacement, and $p(t)$ is the applied force; see Figure 4.

Similarly, the equation of motion of a linear structure with $n$-degree-of-freedom ( $n$-DOF) can be expressed as

$$
M \ddot{X}+C \dot{X}+K X=P(t),
$$

where $M, C$, and $K \in \mathbb{R}^{n \times n}$ are the mass, damping, and stiffness matrices, respectively, $\ddot{X}, \dot{X}$, and $X \in \mathbb{R}^{n \times 1}$ are the relative acceleration, velocity, and displacement vectors, respectively, and $P(t) \in \mathbb{R}^{n \times 1}$ is the external force vector.

The technique of modeling the stiffness parameter $K$ can be on the basis of either a linear (elastic) or a nonlinear (inelastic) component [20]. The linear case means that the relationship between the lateral force and the resulting deformation is linear [21].

When both ground translation and rotation are considered, the motion equation is [22]

$$
M \ddot{X}+C \dot{X}+K X=F-M I_{n} \ddot{a}_{g}
$$




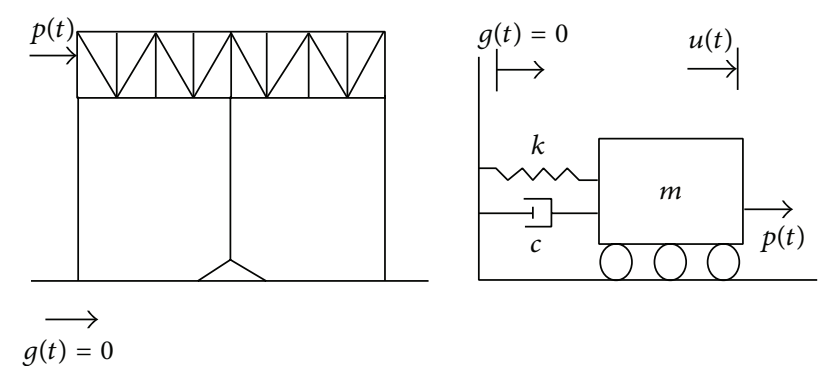

FIGURE 4: A single degree-of-freedom system for one-story building.

where $\ddot{a}_{g}$ represents the earthquake acceleration component, $I_{n}$ is the system influence coefficient vector, $X=\left[x^{T}\right.$, $\left.y^{T}, \theta^{T}\right]^{T}, x=\left[x_{1}, \ldots, x_{n}\right]^{T}, y=\left[y_{1}, \ldots, y_{n}\right]^{T}, \theta=\left[\theta_{1}, \ldots\right.$, $\left.\theta_{n}\right]^{T}, I_{n}=\left[\begin{array}{lll}I_{1} & I_{2} & 0\end{array}\right]^{T}$, and $\ddot{a}_{g}=\left[\begin{array}{lll}\ddot{x}_{g} & \ddot{y}_{g} & 0\end{array}\right]$.

The mathematical analysis of the TC structure yields the following mass matrix, damping matrix, and stiffness matrix:

$$
\begin{aligned}
& M=\left[\begin{array}{lll}
M_{x} & 0_{n x n} & 0_{n x n} \\
0_{n x n} & M_{y} & 0_{n x n} \\
0_{n x n} & 0_{n x n} & J_{0}
\end{array}\right], \\
& K=\left[\begin{array}{ccc}
K_{x x} & 0_{n x n} & -K_{x \theta} \\
0_{n x n} & K_{y y} & K_{y \theta} \\
-K_{x \theta} & K_{y \theta} & K_{\theta \theta}
\end{array}\right],
\end{aligned}
$$

where $J_{0}=\operatorname{diag}\left[m_{1} r_{1}^{2}, \ldots, m_{n} r_{n}^{2}\right], J_{0}$ is the polar moment of inertia of the story, $r$ is the radius of gyration of the floor, $n$ is the number of stories of the building, and $C$ is the damping matrix which is proportional to mass and stiffness matrix by the Rayleigh method [23].

For a simple case, the mass of each floor is concentrated at the floor plate ( $N$-story shear model). Two seismic waves are in the $x$ direction and the $y$ direction. Here the torsional components are zero; see Figure 5. The left figure represents 3dimensional building structures and the right figure exhibits the parameters of each floor. The motion equations show the relative displacements of the building structures with respect to the ground motions [10]:

$$
\begin{aligned}
m_{j} \ddot{x}_{j}+p_{j-1}-p_{j} & =-m_{j} \ddot{x}_{g}(t), \\
m_{j} \ddot{y}_{j}+q_{j-1}-q_{j} & =-m_{j} \ddot{y}_{g}(t), \\
J_{j} \ddot{\theta}_{j}+r_{j-1}-r_{j} & =0,
\end{aligned}
$$

where $x_{j}$ and $y_{j}$ are the $j$ th floor displacements in $x$ direction and $y$ direction, respectively, and $\theta_{j}$ is the $j$ th floor torsion angle relative to the ground. $p_{j-1}$ and $q_{j-1}$ are the $j$ th floor column shear forces in $x$ direction and $y$ direction, $p_{j}$ and $q_{j}$ are the $j+1$ th floor column shear forces in $x$ direction and $y$ direction, respectively, $r_{j-1}$ is the $j$ th floor torque generated by the shear forces, $r_{j}$ is the $j+1$ th floor torque, $m_{j}$ is the mass of the $j$ th floor, and $J_{j}$ is the rotational inertia. In the above motion equation, the $\ddot{x}_{g}(t)$ and $\ddot{y}_{g}(t)$ are the ground
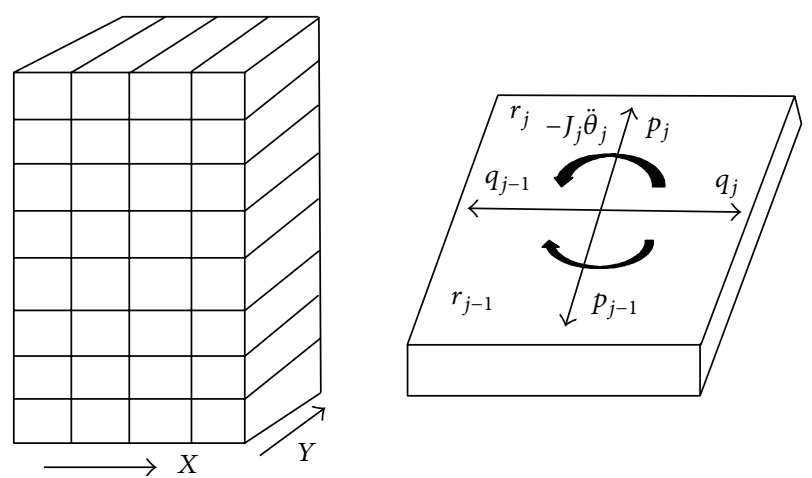

FIGURE 5: Three-dimensional building structures with parameters of each floor.

accelerations that strike the building structures due to an earthquake. The total forces exerted on each floor of the buildings in $x$ and $y$ directions are multiplied by the mass of the building at each floor. The torsional components of the ground acceleration are neglected and so the right hand side of the third equation is zero. The movement of the buildings in $x$ and $y$ directions, that is, the acceleration components, are $\ddot{x}_{j}$ and $\ddot{y}_{j}$, respectively. Due to the bidirectional motion of the building, there will be coupling action on the building which gives rise to the torsional motion in the building which is denoted by the component $\ddot{\theta}_{j}$.

If we only consider $x$-axis seismic wave, the torsion effect on the building is in $x$-component [24]; see Figure 6 . The motion equations are

$$
\begin{aligned}
p_{j-1}= & K_{j}\left(x_{j}-x_{j-1}\right)+C_{j}\left(\dot{x}_{j}-\dot{x}_{j-1}\right) \\
& +B_{j}\left(\theta_{j}-\theta_{j-1}\right)+D_{j}\left(\dot{\theta}_{j}-\dot{\theta}_{j-1}\right), \\
r_{j-1}= & B_{j}\left(x_{j}-x_{j-1}\right)+D_{j}\left(\dot{x}_{j}-\dot{x}_{j-1}\right) \\
& +E_{j}\left(\theta_{j}-\theta_{j-1}\right)+F_{j}\left(\dot{\theta}_{j}-\dot{\theta}_{j-1}\right), \\
r_{j}= & B_{j+1}\left(x_{j+1}-x_{j}\right)+D_{j+1}\left(\dot{x}_{j+1}-\dot{x}_{j}\right) \\
& +E_{j+1}\left(\theta_{j+1}-\theta_{j}\right)+F_{j+1}\left(\dot{\theta}_{j+1}-\dot{\theta}_{j}\right),
\end{aligned}
$$

where $K_{j}=\sum_{i=1}^{I} K_{j, i}, C_{j}=\sum_{i=1}^{I} C_{j, i}, B_{j}=\sum_{i=1}^{I} K_{j, i} l_{j, i}, D_{j}=$ $\sum_{i=1}^{I} C_{j, i} l, E_{j}=\sum_{i=1}^{I} K_{j, i} l_{i, j}^{2}, F_{j}=\sum_{i=1}^{I} C_{i, j} l_{i, j}^{2}, K_{j, i}$ and $C_{j, i}$ are the stiffness and viscous damping coefficient, respectively, of the $i$ th plane frame at the $j$ th floor, $m_{j}$ is the mass of the $j$ th floor, $J_{j}$ is the moment of inertia of the $j$ th floor, $l_{j, i}$ is the distance of mass centre of the $j$ th floor to the $i$ th plane frame, and $I$ is total number of plane frames. $l_{j, i}$ is positive if the $i$ th plane frame is located on the left of the mass centre; otherwise, it is negative.

\section{Bidirectional Structural Control Devices}

Vibration suppression in appropriate quantity can prevent the structures from fracture or collapse. Some devices play this suppression role to prevent the structure from damage. The 


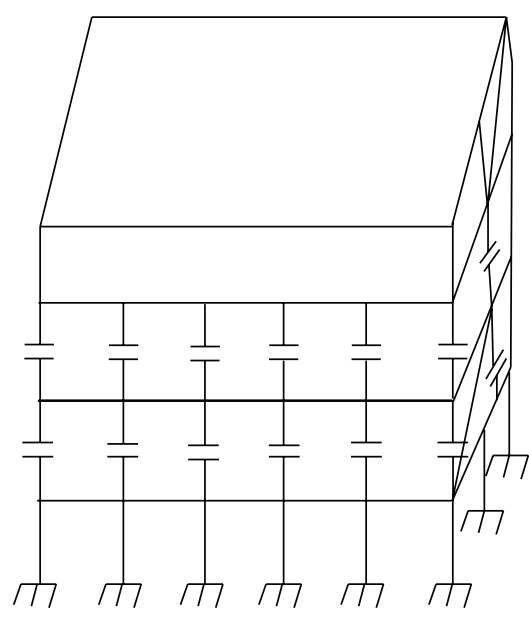

FIgURE 6: The torsion effect on the building is in $x$-component.

control devices, such as actuators, isolators, and dampers, are installed to suppress the external vibrations. These structural control devices are getting more popularity and attention along with their applications in building structures. The structural control devices for the seismic hazards can be categorized as passive, active, hybrid, and semiactive [25]. In the last two decades, the active, semiactive, and hybrid control are paid more attention compared to the passive devices [26]. The conception and characteristic of the structural control devices for bidirectional seismic waves are illustrated below.

3.1. Passive Devices. A passive control device is incorporated to a structure. It modifies the stiffness or the damping of the structure in an suitable way. The passive control system does not require an external power source for its operation. It generates control force opposite to the motion of controlled structured system [27]. The passive systems can be divided into two basic categories: (1) base isolation systems and (2) energy dissipation systems.

There are many passive control devices, for example, viscoelastic dampers, tuned mass dampers, frictional dampers, tuned liquid dampers, and base-isolation systems [28]. The principal function of a passive energy dissipation system is to reduce the inelastic energy dissipation demand on the framing system of a structure [29].

The forces of the passive control devices solely depend on the structural motion. They can be expressed as [7]

$$
f_{i}(t)=-c_{i} \dot{x}_{d i}(t),
$$

where $\dot{x}_{d i}$ is relative velocity across $i$ th device and $c_{i}$ is the damping coefficient associated with the $i$ th device.

We use the following sections to describe some famous dampers for the bidirectional control.

The tuned mass damper (TMD) is considered to be an energy dissipation system, although the primitive concept of this system is not to dissipate energy. It transfers the energy from the building structure to the tuned mass dampers (absorbers). The basic principle of TMD is to obtain optimal damping parameters, in order to control the displacement of an undamped system subjected to a harmonic force [30].
The coupled lateral-torsional motions under seismic excitations are exhibited by the building structures with intended eccentricities between their mass and stiffness centers. Reference [31] investigated tuned mass dampers in arrangements termed as coupled tuned mass dampers (CTMDs), where translational springs and viscous dampers are used to connect mass in an eccentric manner. The CTMD works in coupled mode that includes lateral and rotational vibration. This technology is utilized to control coupled lateral and torsional vibrations of asymmetric buildings. The results revealed that CTMDs are more effective and robust in controlling coupled lateral and torsional vibrations of asymmetric buildings. Reference [32] had proposed multiple tuned mass dampers (MTMDs) with distributed natural frequencies. Several researches had been carried out to establish the effectiveness of multiple tuned mass dampers and it had been verified that MTMDs had advantages over single TMD. A multiple tuned mass damper (MTMD) system is shown in Figure 7. It consists of a main system, which has $n$ tuned mass dampers with different dynamic characteristics. The main system is subjected to a lateral force. The main system and each TMD vibrate in the lateral direction. Due to torsional coupling, the main system has torsional vibration. The total degrees-of-freedom of the combined system is $n+2$. Two uncoupled frequency parameters of the main system are defined by

$$
\begin{aligned}
w_{s x y} & =\sqrt{\frac{K_{s x y}}{m_{s x y}},} \\
w_{\theta} & =\sqrt{\frac{K_{\theta}}{m_{s x y} r_{s}^{2}},} \\
m_{s x y} & =\left[\begin{array}{ccc}
M_{x} & 0 & 0 \\
0 & M_{y} & 0 \\
0 & 0 & J_{0}
\end{array}\right], \\
K_{s x y} & =\left[\begin{array}{ccc}
K_{x x} & 0 & -K_{x \theta} \\
0 & K_{y y} & K_{y \theta} \\
-K_{x \theta} & K_{y \theta} & K_{\theta \theta}
\end{array}\right],
\end{aligned}
$$

where $m_{s x y}$ is the mass of the main system, $K_{s x y}$ is the main system lateral stiffness, $K_{\theta}$ and $r_{S}$ are the torsional stiffness and radius of gyration, respectively, related to the main system about the center of mass, and $J_{0}$ is the polar moment of inertia related to the story.

Tuned liquid column damper (TLCD) has uniform crosssection with $U$ shaped tube attached. The schematic view has been shown in Figure 8. The vibrational energy from the structure is transferred to the TLCD liquid via the movement of the rigid TLCD container, thus stimulating the TLCD liquid.

Reference [33] investigated the methodology of vibration control of eccentric structures using TLCD modeled as torsionally coupled multistory shear structures which is under the grip of multidimensional seismic excitations. For a multistory eccentric model with TLCD arrangements, $O, S$, and $M$ 


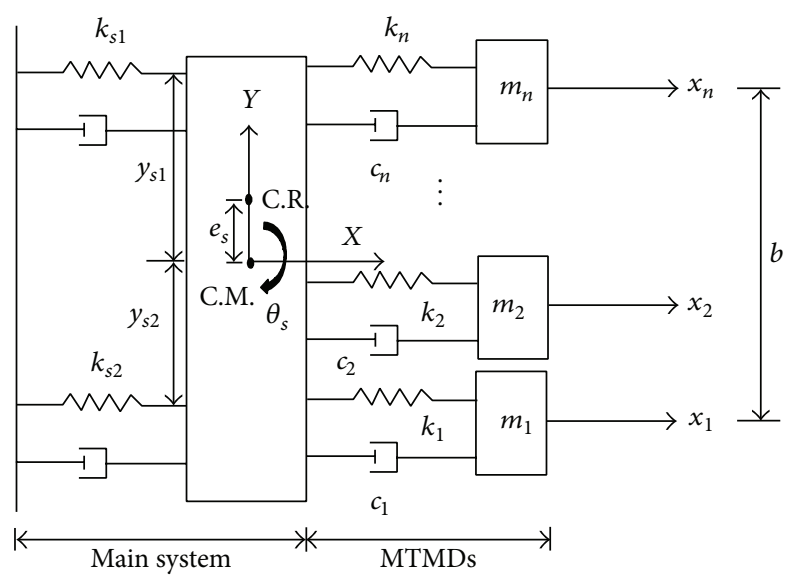

FIGURE 7: The multiple tuned mass damper (MTMD).

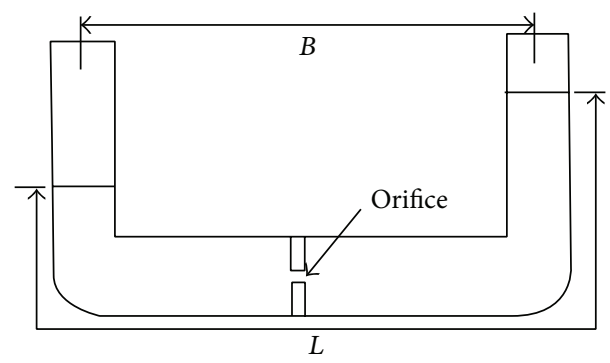

Figure 8: The tuned liquid column damper.

are the geometry, stiffness, and mass centers, respectively, with $u, v$ denoting floor translational displacement along $x$ axis and $y$-axis, respectively, and $\theta$ denoting the rotational angle about vertical $z$-axis. The equation of motion along $x$ and $y$ directions is illustrated by

$$
\begin{gathered}
m_{h} \ddot{h}+c_{h} \dot{h}+k_{h} h=-\rho A_{h} B_{h}\left[\ddot{x}_{l}+\ddot{u}_{g}-l_{v h}\left(\ddot{\theta}_{l}+\ddot{\theta}_{g}\right)\right], \\
m_{s} \ddot{s}+c_{s} \dot{s}+k_{s} s=-\rho A_{s} B_{s}\left[\ddot{y}_{l}+\ddot{v}_{g}+l_{u s}\left(\ddot{\theta}_{l}+\ddot{\theta}_{g}\right)\right],
\end{gathered}
$$

where $m_{h}=\rho A_{h} L_{h}, m_{s}=\rho A_{s} L_{s}, c_{h}=(1 / 2) \rho A_{h} \xi_{h}|\dot{h}|, c_{s}=$ $(1 / 2) \rho A_{s} \xi_{s}|\dot{s}|, k_{h}=2 \rho A_{h} g, k_{s}=2 \rho A_{s} g$. Natural frequencies are $\omega_{h}=\sqrt{k_{h} / m_{h}}=\sqrt{2 g / L_{h}}, \omega_{s}=\sqrt{k_{s} / m_{s}}=\sqrt{2 g / L_{s}}$, $\rho=$ Liquid Density, $\xi_{h}$ and $\xi_{s}$ are damping ratios related to TLCD, and $h$ and $s$ are the displacements of liquid in the TLCD of $u$ and $v$ directions. $L_{h}$ and $L_{s}, B_{h}$ and $B_{s}$, and $A_{h}$ and $A_{s}$ are the notations for length, width, and cross sectional, respectively, of the liquid in two TLCDs. Coordinate positions of the TLCDs in $x$ direction are represented by $l_{u h}$ and $l_{v h}$. Coordinate positions of the TLCDs in $y$ direction are represented by $l_{u s}$ and $l_{v s} . \ddot{u}_{g}, \ddot{v}_{g}$, and $\ddot{\theta}_{g}$ are the ground seismic acceleration along $u, v$, and $\theta$ directions. $\ddot{x}_{l}, \ddot{y}_{l}$, and $\ddot{\theta}_{l}$ are the accelerations of the $i$ th floor along $x, y$, and $\theta$ directions.

The circular tuned liquid column damper (CTLCD) is shown in Figure 9. This advanced control device is highly responsive to the torsion. CTLCD can be applied for both torsional vibration and torsionally coupled vibration. The effectiveness of CTLCD for the structural torsional response

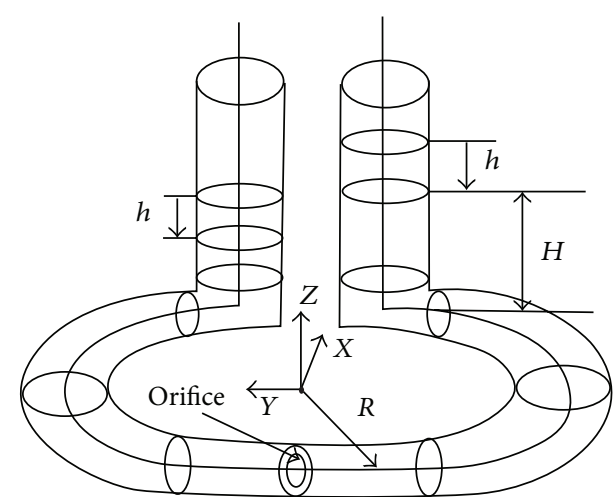

FIgURE 9: The circular tuned mass damper (CTLCD).

is studied by [34]. Stochastic vibration theory is applied to identify the optimal parameters of CTLCD in [35]. The motion equation of CTLCD is given by [36]

$$
\begin{aligned}
\rho A & (2 H+2 \pi R) \ddot{h}+\frac{1}{2} \rho A \xi|\dot{h}| \dot{h}+2 \rho A g h \\
& =-2 \rho A \pi R^{2}\left(\ddot{u}_{\theta}+\ddot{u}_{g \theta}\right),
\end{aligned}
$$

where $R$ is the radius of the horizontal circular column, $\ddot{u}_{\theta}$ is the structures torsional acceleration, and $\ddot{u}_{g \theta}$ is the torsional acceleration of ground motion.

Reference [9] presents a new type of control device termed as tuned liquid mass damper (TLMD), to control the torsional response of building structures subjected to bidirectional earthquake waves. The mass of TLMD includes both TLCD tank and the liquid in the tank. The stiffness is compensated by natural rubbers. The main working concept of TLMD is to operate a TLCD in one direction and run a TMD in the other orthogonal direction; see Figure 10.

The stiffness of TMD and the liquid high are determined as

$$
\begin{aligned}
& k=m\left(2 \pi f_{m}\right)^{2}, \\
& L=\frac{2 g}{\left(2 \pi f_{L}\right)^{2}},
\end{aligned}
$$

where $m$ and $f_{m}$ are the mass and the tuned frequency in the TMD control direction and $g$ and $f_{L}$ are the gravity acceleration and the tuned frequency of TLCD.

Tuned liquid column dampers (TLCDs) are a special type of TLDs that depends on the motion of a column of liquid in a U-tube-like container to neutralize the forces acting on the structure. The introduction of the damping factor is done in the oscillating liquid column through an orifice in the liquid passage. The damping, however, unlike TMDs, is amplitude dependent, and thus the TLCD dynamics are associated with nonlinearity. On the other hand, circular tuned liquid column dampers (CTLCDs) are very much active when exposed to torsional response. As the earthquake is practically multidimensional, the torsionally coupled vibration factor cannot be ignored and so CTLCD is much favored in this case. Reference [37] had discussed 


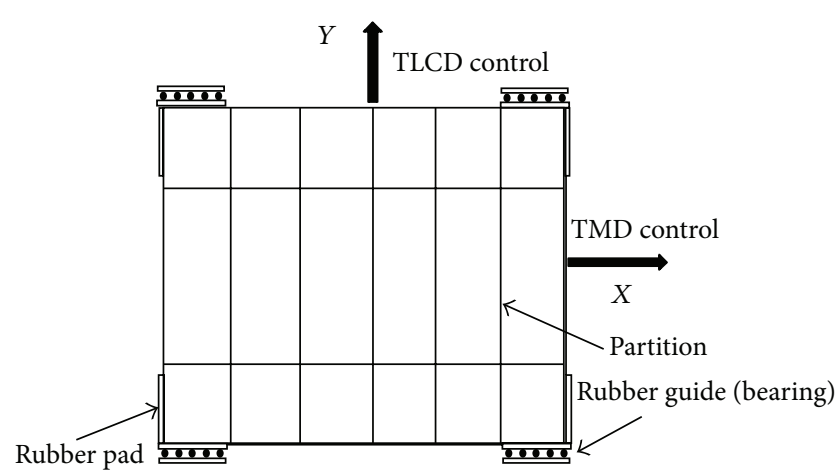

FIGURE 10: The tuned liquid mass damper.

the control performance of the novel sealed, torsional tuned liquid column gas damper (TTLCGD) in order to minimize the coupled flexural torsional response of plan-asymmetric buildings under the grip of seismic loads. The analysis of technique associated reveals that TTLCGD is an effective control device in suppressing the time-harmonic excitation and the earthquake response.

3.2. Active Devices. The main drawback of the passive control devices is that they cannot adapt the change of the natural frequency caused by the structural nonlinearities and huge seismic excitations, especially for multiple floor buildings [1], although multiple and tuned dampers can be applied for different frequencies.

Since 1970s, remarkable progress has been made in the field of active control of civil engineering structures subjected to natural forces such as winds and earthquakes [26]. The active structure control modifies the structural motion by some external forces. Topics covered on active structural control can be found in [38]. Compared with the passive devices, the active systems have the following advantages [28]:

(1) Motion control can be achieved with greater effectiveness.

(2) In account of ground motions, it is relatively insensitive.

(3) It can be applied to the multihazard remission circumstances.

(4) Control objectives can be selected flexibly.

In order to control actively, the external excitations and inner structural responses are needed. Measured information is sent to the control algorithm to generate desired control forces. So the active devices usually use displacement sensors.

The active tuned mass damper (ATMD) uses control strategy to improve the tuned mass damper (TMD). It improves the effectiveness in minimizing the structural response [39]. As the proof of [40], the qualities of TMD can be enhanced by introducing an active force between the structure and the TMD. ATMD methodology can be also regarded as a modification version of ATMD, robustness version of TMD.

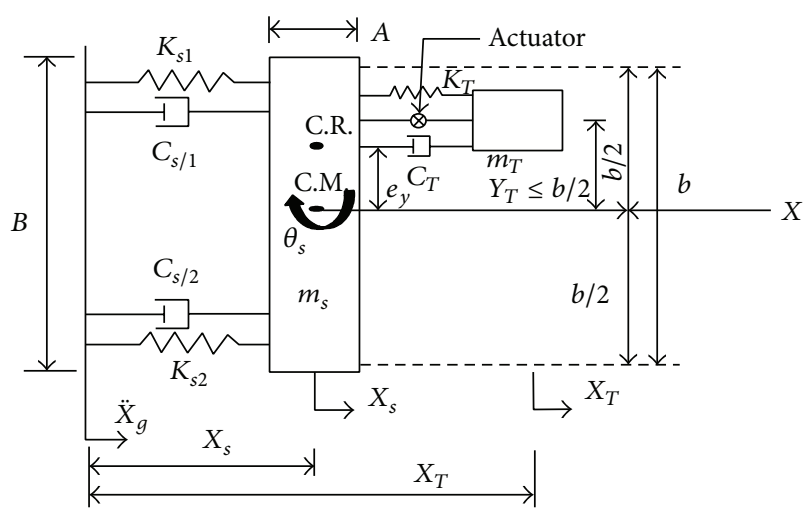

FIGURE 11: The active tuned mass damper for a 2-DoF structure.

The active controller should be able to absorb the translation-torsion coupled vibrations. Besides the translational vibrations, the torsional vibrations under the seismic waves also affect the performance of ATMD. An asymmetric structure under the coupled lateral-torsional responses is discussed in [41]. The lateral displacement of asymmetric structures and the optimum parameters incorporated in ATMD are shown by a two-degree-of-freedom (2-DoF) structure; see Figure 11. The mathematical expression of the ATMD active control force that is generated is

$$
\begin{aligned}
U(t)= & -m_{t} \ddot{x}_{s}-c_{t}\left[\dot{x}_{T}-\left(\dot{x}_{s}+y_{T} \dot{\theta}_{s}\right)\right] \\
& -k_{t}\left[x_{T}-\left(x_{s}+y_{T} \theta_{s}\right)\right],
\end{aligned}
$$

where $m_{t}$ is the feedback gain of acceleration associated with asymmetric structure, $c_{t}$ is the feedback gain of the velocity of the ATMD, and $k_{t}$ is the feedback gain of the displacement of the ATMD. Reference [42] had proposed a new performance index for active vibration control of three-dimensional structures. To analytically proof the existence of the proposed performance index, a six-story three-dimensional structure is taken into consideration as an example with a fully active tendon controller system implemented in one direction of the building. The building under analysis is modeled as a structure made up of members joint by a rigid floor diaphragm in a manner so that it has three degrees of freedom at each floor, lateral displacements in two perpendicular directions, and a rotation with respect to a vertical axis for the third dimension.

3.3. Semiactive Devices. Semiactive control devices are regarded as controllable passive devices. The main objective of these devices is saving control resources. The actuators of the semiactive control do not add mechanical energy to the structure directly. The power break down semiactive control system offers some degrees of protection with the help of embedded passive components.

The semiactive devices take the advantages of the passive and the active control. It requires less power than the active control devices. They can even be operated by the battery in the case of power failure during the seismic event [26]. They perform significantly better than passive devices. 


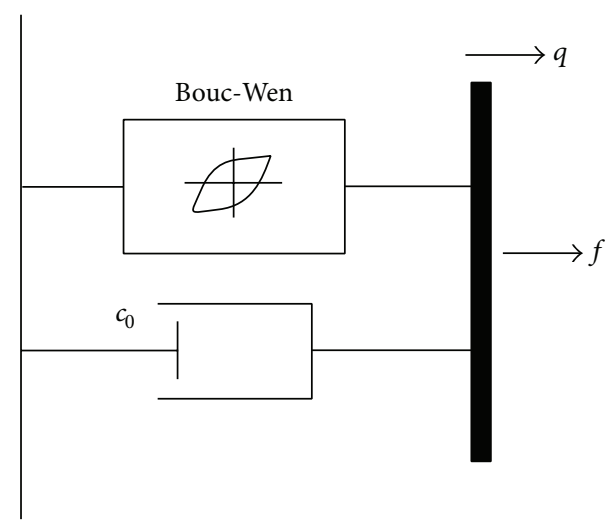

Figure 12: Simple mechanical model of MR.

An exhaustive review on the semiactive devices is proposed in [25].

The magnetorheological (MR) damper is the most popular semiactive damping device. It works on the magnetorheological fluid and is controlled by a magnetic field. Generally, the magnetic field is produced by electromagnet. It requires minimal power for its operation. The suspended minute iron particles in a base fluid are termed as MR fluids. This type of liquids has the capability of changing from free flowing linear viscous state to semisolid state with controllable yield strength under a magnetic field.

The result of uncovering the liquid to a magnetic field is the particles use the form of chains. These chains obstruct the flow and solidify the fluid in a span of milliseconds. The stress is directly proportional to the magnitude of the applied magnetic field [43]. The behavior of MR fluid can be simulated by the Bingham plastic model, which is an extension of the Newtonian flow. The other way of determining the behavior of MR fluid is to analyze the yield stress of the fluid. The total stress is given by [44]

$$
\tau=\tau_{y} \operatorname{sgn}(\dot{\gamma})+\eta \dot{\gamma}
$$

where $\tau_{y}$ is the yield stress induced by the magnetic field, $\dot{\gamma}$ is the shear rate, and $\eta$ is the viscosity of the fluid.

The application of MR damper to control the torsional and torsionally coupled responses subjected to bidirectional seismic waves is investigated in [45]. The MR damper contributes significantly to the field of civil engineering. The simple mechanical model of MR is shown in Figure 12. In [46], a prototype shear-mode MR damper is proposed.

The governing force $f$ generated by MR device is

$$
\begin{aligned}
& f=c_{o} \dot{q}+\alpha z, \\
& \dot{z}=-\gamma|\dot{q}||z||z|^{n-1}-\beta \dot{q}|z|^{n}+A \dot{q},
\end{aligned}
$$

where $q$ is the device displacement, $z$ is the evolutionary variables that keeps track of the response history dependence, and $\gamma, \beta, n$, and $A$ can control the linearity in the unloading and the smoothness of the transition from the preyield to the postyield region.

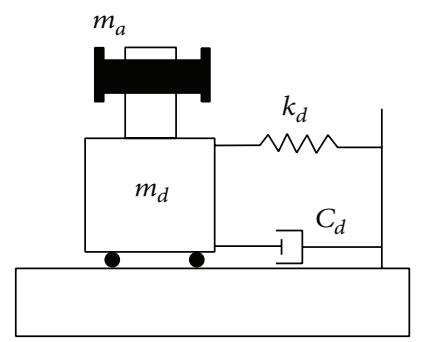

FIGURE 13: HMD system installed in $n$th floor.

3.4. Hybrid Devices. Hybrid base isolation (HBI) had been a matter of interest for a number of researchers due to its effectiveness and consists of a passive base isolation system combined with a control actuator to generate the effects of the base isolation system. Several research on base isolation system has been carried out and installed in several structural engineering projects due to its positive attributes like simplicity, reliability, and effectiveness. Reference [47] has proposed the application of HMD system consisting of tuned mass damper and active mass damper to control torsionally coupled building structures under bidirectional seismic force. In this context, the fuzzy logic controller is used to control the HMD system. The schematic view is shown in Figure 13.

The equation of motion for HMD system installed in $N$ story building is given by

$$
M_{h} \ddot{u}_{h}+C_{h} \dot{u}_{h}+K_{h} u_{h}=-M_{h} P_{h} \ddot{u}_{a N}+K_{h} P_{c} u_{c},
$$

where the mass, damping, and stiffness matrices of the HMD system are $M_{h}, C_{h}$, and $K_{h}$, respectively. $u_{h}$ is a vector of displacements of the HMD system relative to the $N$ th floor. $P_{h}$ and $P_{c}$ are position vectors of the absolute acceleration of $N$ th floor, $\ddot{u}_{a N}$, and control command vector $u_{c}$, respectively. Reference [48] had investigated hybrid damper-TLCD control system to control 3D coupled irregular buildings subjected to bidirectional seismic waves. Simulation results for control of two multistory moment resisting space steel structures with vertical and plan irregularities show clearly that the hybrid damper-TLCD control system significantly reduces responses of irregular buildings subjected to various earthquake ground motions and increases reliability and maximum operability during power failure. The comparison between uncontrolled, passive control, active control, semiactive control, and hybrid control devices are demonstrated by Figure 14 .

\section{Bidirectional Vibration Control}

The appropriate design of a controller is utterly necessary so that it can send essential control signal to the control devices in order to reduce the structural responses. The main strategy involved within the control scheme to prevent the collapse of building structures under bidirectional seismic waves is to control the coupled translation-torsion response of the building structures [49-52]. In this section, various control strategies on the basis of various techniques are presented. The main object of the bidirectional control is to change 


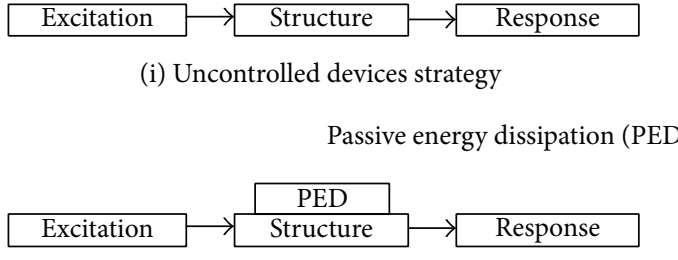

(ii) Passive control devices strategy

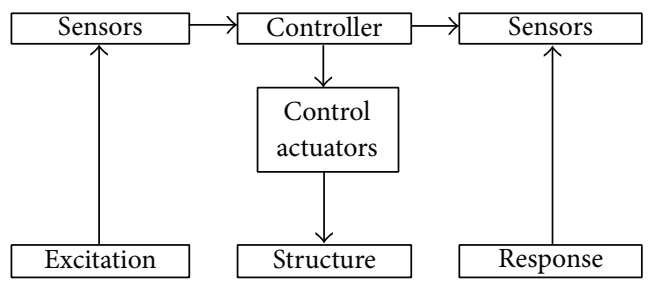

(iii) Active control devices strategy

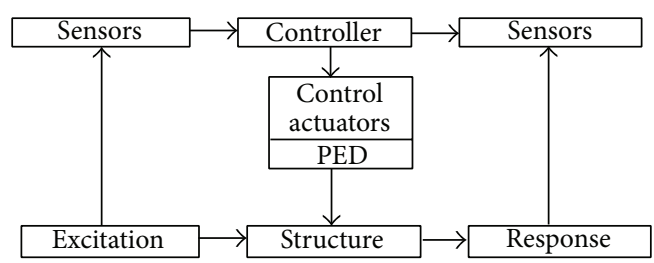

(iv) Semiactive control devices strategy

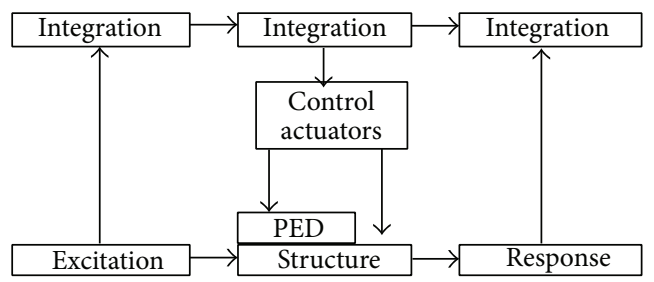

(v) Hybrid control devices strategy

Figure 14: Comparison of control devices.

the coupled translation-torsion response of the building structure, in order to prevent the collapse of building under bidirectional seismic waves [53]. Robustness, fault tolerance, simplicity, and reliability criteria are considered [54].

4.1. Time Delay Problem in Vibration Control. Time delay from the measurement to the actuator is a limit for vibration control. The control loop includes vibration data measurement, data filtration, control algorithm, data transmission, and actuation. The control loop has also phase shift by time delay [55]. The time delay may cause instability in the closedloop [56].

The motion equation of $n$-DoF structure with time delay $t_{d}$ is

$$
M \ddot{x}(t)+C \dot{x}(t)+K x(t)=\Gamma u\left(t-t_{d}\right)-M \Lambda \ddot{x}_{g}(t) .
$$

If $t_{d}$ is fixed, the Laplace form transformation is

$$
F_{d}(s)=e^{-s t_{d}}\left(g_{1} s+g 2\right) .
$$

A review on time-delay compensation methods can be found in [57].

4.2. Optimal Placement. The proper placement of sensing and control devices is an important research field of structural control. It gives the measurement and control operation effectively. It also affects the controllability and observability of the controlled system [58,59]. Reference [60] shows that the location performance index of the actuator and sensor can be computed by the Hankel singular values $\gamma_{w z}^{2}$ and $\gamma_{u y}^{2}$ :

$$
k^{2}=\frac{\left(\gamma_{w z}^{2}\right)^{T} \gamma_{u y}^{2}}{\left\|\gamma_{w z}^{2}\right\|_{z}\left\|\gamma_{u y}^{2}\right\|_{z}},
$$

where $k$ is the nonnegative correlation coefficient, $\gamma_{w z}^{2}$ and $\gamma_{u y}^{2}$ denote the Hankel singular values of the transfer functions $G_{w z}$ and $G_{u y}, u$ and $w$ represent the input to the system, and $y$ and $z$ represent the output of the system. Reference [61] suggests that the sensor is placed at the center of mass. Reference [61] shows that the center of mass may not be good for the sensor position. Arbitrary arrangement of sensors is better subjected to bidirectional seismic motion. Reference [2] presents a detail survey on the optimal placement of control devices. Reference [24] uses energy dissipation to analyze the position of the controller, in order to minimize translation-torsion coupling effects. It suggests that the locations which are nearby to the geometric centre of the structure can minimize the torsional effect.

4.3. Linear Controllers. The working principle of PID controller is based on the feedback error $e(t)$ which is otherwise used to calculate the required control force. In case of structural applications if the desired state is in the equilibrium position then the reference signal is considered to be taken as zero. The principle of PID control is to use the feedback error $e(t)$, which is the difference between the output signal $y(t)$ and the reference signal $r(t)$. Once the error is calculated, the main aim of the controller is to minimize the error for the next iteration process by carefully manipulating the inputs. It has the following form:

$$
u(t)=K\left[e(t)+\frac{1}{T_{i}} \int e(t) d t+T_{d} \frac{d e(t)}{d t}\right],
$$

where $K$ is the proportional gain, $T_{i}$ is the integral time, and $T_{d}$ is the derivative time, $e(t)=r(t)-y(t)$. PID control is a negative feedback algorithm. It can force $e(t)$ to zero. It is the most popular industrial controller. Reference [42] uses MR damper with the MR-MD scheme for PID to control a threedimensional structure with bidirectional seismic excitations. The aim of the controller is to calculate the essential forces to control the structural vibrations. Reference [62] investigates the effectiveness of active tendon PID control implemented in a single-story torsionally coupled structure. A comparison between a sliding mode control and PID control for the structural system is investigated by [63]. Reference [64] had 
investigated the effects of measuring seismic waves on a sixstory asymmetric structural model compiled with frictional dampers. The methodology deals with the control of torsional response of asymmetric structures and to obtain a lower level of torsional balance by arranging empirical centre of balance (ECB) of the structure at same distance from the edges of the building plan. The axial displacement of each actuator is controlled using a conventional PID controller. In this research, frictional dampers proved their effectiveness of controlling lateral-torsional coupling of torsionally flexible as well as stiff structures.

The most important optimal controllers are the linear quadratic regulator (LQR) and linear quadratic Gaussian (LQG) control. The equation of motion can be exhibited in the form mentioned below:

$$
\dot{X}=A x+B u
$$

where the state and input system matrices are $A$ and $B$, respectively. The LQR algorithm calculates a control law $u$ in the form of criteria of performance or cost function:

$$
\begin{aligned}
J= & \int_{0}^{\infty}\left(x_{\mathrm{ref}}-x(t)\right)^{T} \mathrm{Q}\left(x_{\mathrm{ref}}-x(t)\right) \\
& +u(t)^{T} R u(t) d t
\end{aligned}
$$

is minimal. The design matrices $Q$ and $R$ take back the compensation on the deviations of state variables from their setpoint and the control actions, respectively.

The increase in elements of $Q$ results in the increase of cost function, the compensation associated with any track change from the desired set-point of that state variable, and thus the specific control gain will be larger. The increase in $R$ matrix results in a larger penalty that is applied to the audacity of the control action, and the control gains are uniformly decreased. The feedback gain of the optimal control is computed by minimizing a cost function $J=$ $J(z, t, u(t))[55]:$

$$
J=\lim _{\tau \rightarrow \lambda} \frac{1}{\tau} E\left[\int_{0}^{\tau}\left\{y_{r}^{T} Q y_{r}+f^{T} R f\right\} d t\right] .
$$

Reference [65] presents a semiactive control to the coupled translational and torsional vibration of a 2-story asymmetric building subjected to seismic excitations. A LQG controller is involved as a nominal linear controller, considering the ground acceleration with white noise. The LQG controller is given by

$$
\begin{aligned}
\stackrel{\circ}{z} & =(A-L C) \hat{z}+L y_{m}+(B-L D) f_{m}, \\
f_{c} & =-K \widehat{z},
\end{aligned}
$$

where $L$ is the state estimator gain matrix and $K$ is the LQR gain matrix. The authors [66] in their research implemented active isolation and conducted experiments in order to verify the behavior of seismically excited buildings under multidirectional earthquake force. Active isolation technique works in combination with base isolation system and controllable actuators. The base isolation methodology offers effective approach in reducing interstory drifts and floor accelerations that works in phase with the adaptive nature of the active system in order to generate higher level performance against wide range of earthquakes. In this methodology, LQG control steps are obtained using LQR and Kalman estimator. The optimal control gain is achieved using the following:

$$
u(t)=-K \bar{x}(t)
$$

where $K$ is optimal control gain with respect to the states of the augmented system. The authors [48] had researched the control of 3D coupled irregular buildings subjected to bidirectional seismic waves. To find the optimal control forces, a wavelet based algorithm involving optimal control is utilized. It has been suggested in their work that LQR or LQG algorithm can be used as a control algorithm for the feedback controller as per the investigation mentioned $[28,67,68]$. The authors [69] in their study suggested a sequential optimal control for serially connected isolated structure subjected to bidirectional earthquake. Sequential control algorithm has inherent capabilities to construct control objective function under bidirectional earthquake situations. The objective function which is in quadratic form can be illustrated as in (41)

$$
\begin{aligned}
J= & \int_{t_{0}}^{t_{f}}\left[\frac{1}{2}\{X(t)\}^{T}[Q]\{X(t)\}\right. \\
& \left.+\left\{f_{c}(t)\right\}^{T}[R]\left\{f_{c}(t)\right\}\right],
\end{aligned}
$$

where weighted matrices $Q$ and $R$ represent structure response and control force. $x, y$ structural response is contained in $X(t), t_{0}$ is control starting time, and $t_{f}$ is control conclusion time. The mathematical expression of sequential optimal control is depicted by the following equations:

$$
\begin{aligned}
\left\{f_{c}\left(t_{A}\right)\right\} & =-[R]^{-1}[B]^{T}\left\{\lambda\left(t_{A}\right)\right\}, \\
\{\dot{\lambda}\} & =-[A]^{T}\{\lambda\}-[Q]\{X\}, \\
\left\{\lambda\left(t_{f}\right)\right\} & =0, \\
\{\dot{X}\} & =[A]\{X\}+[B]\{f\}_{c}+\{E\} \ddot{U}_{g}^{T},
\end{aligned}
$$

where $t_{A}$ is current time, the domain is expressed in $\left[t_{A}, t_{f}\right]$, and the value of $\lambda$ can be computed directly.

The result of the entire analysis was in the favour of the algorithm not only being an effective measure to control the bidirectional horizontal response of earthquake but also reducing the isolation layer movement by large extent. Reference [70] investigated the lateral-torsional earthquake response control of two single-story asymmetric plan buildings associated with multiple magnetorheological (MR) dampers. The desired control forces are generated using LQR technique. The damper forces are extracted using the method of least square minimization. Reference [71] investigates the response related to seismic and harmonic waves for a true free-plan tall building equipped with two tuned inertial 
masses (TMs) and magnetorheological (MR) dampers. The technique of LQR strategy is hold as a benchmark in order to compare the performance with the proposed physical controller. A 21-story $R / C$ structure building is investigated of typical story height of $3.6 \mathrm{~m}$ with total height of $90 \mathrm{~m}$. In the $y$ direction, the building being more flexible, there is existence of lateral torsional coupling. As a result, two TMs, one along the flexible edge and one along the stiff edge of the building, were designed and built on the 21st story. The controller used in this investigation is quite similar to the LQR controller which was implemented to control TM-MR damper.

$H^{\infty}$ control methodology has been relied as an effective approach in structural vibration control which is classified as linear robust control. This scheme is unresponsive to the disturbances and parametric differences and so it is most preferred for multiple input multiple output (MIMO) type structural control systems [72]. Design method of $H^{\infty}$ control system and its effectiveness was presented by [73]. The analysis was carried out on actual 23-story building in Tokyo using a pair of hybrid mass dampers. Bidirectional seismic excitations were considered during the investigation. The control technique was established by taking into consideration $x$ direction and $y$ direction separately. The bending component of the vibration was controlled along $x$ direction only while along the $y$ direction, control of bending and torsion are considered. The scheme of the control system is shown in Figures 15 and 16.

$H^{\infty}$ control theory was applied to design the controller on the basis of reduced order model depicted in

$$
\begin{gathered}
\dot{x}_{r}=A_{r} x_{r}+B_{r} u+D_{r} w, \\
y=\left[\xi_{1}+l \xi_{3} z\right]^{T}=C_{r} x_{r} .
\end{gathered}
$$

The designed controller should follow the following inequality:

$$
\left\|\begin{array}{l}
W_{1}(s) N(s) \\
W_{2}(s) M(s)
\end{array}\right\|_{\infty}<1,
$$

where $N(s)$ and $M(s)$ mean the transfer function from external input to control input and from external force to output, respectively.

The controller was installed and then the vibration tests are performed. These test results suggested that the control action generated was effective and as per the design. Reference [74] has elaborated the use of a robust optimal $H^{\infty}$ control for the two AMD systems. The AMD system was placed on the top of the irregular building for the vibration control. The building was subjected to bidirectional seismic excitations. The $H^{\infty}$ control uses the technique of LMIbased solution blended with robustness specifications. For an uncertain structural system, the efficient and necessary control forces are determined and then optimized using $H^{\infty}$ control via LMI as illustrated in

$$
\begin{aligned}
(M+\Delta M) \ddot{v}+(C+\Delta C) \dot{v}+(K+\Delta K) v \\
=(M+\Delta M) E w(t)+B_{s} u(t),
\end{aligned}
$$

where $\Delta M, \Delta K, \Delta C$, and $\Delta B_{s}$ are corresponding disturbances. The bound condition satisfied by $\Delta M$ is given by $\left\|\Delta M M^{-1}\right\| \leqslant$ $\|\delta\| \leqslant 1$.

Then using the above criteria, the state space equation can be written as

$$
\dot{Z}(t)=(A+\Delta A) Z(t)+(B+\Delta B) u(t)+H w(t) .
$$

Considering linear time invariant criteria for the above state space equation, the performance index is given by

$$
J=\int_{0}^{\infty}\left(Z^{T}(t) Q Z(t)+u^{T}(t) R u(t)\right) d t,
$$

where $Q \geqslant 0$ and $R>0$ are weighted matrix. $H^{\infty}$ direct output feedback control of buildings under bidirectional acceleration considering the effects of soil-structure interaction was investigated by [18]. In the investigation, the tendon displacement vector of feedback control with direct approach was found to be as depicted by

$$
U(t)=G Y(t)
$$

where $G$ is a time-invariant feedback gain matrix of $4 x s . H^{\infty}$ control algorithm was used to find the entries of $G$ matrix.

\subsection{Nonlinear Controllers}

4.4.1. Sliding Mode Control. The sliding mode control (SMC) is designed for uncertain nonlinear systems [72]. It is very much effective in terms of robustness against the changes in the parameters and external disturbances. It has been successfully applied for structural control [75].

The control force of sliding mode control is

$$
u\left(\widehat{v}_{c}, t\right)=u_{\mathrm{eq}}\left(\widehat{v}_{c}, t\right)-\rho \operatorname{sgn}\left(\sigma\left(\widehat{v}_{c}\right)\right),
$$

where $u_{\mathrm{eq}}$ is the linear part of control force, $\sigma\left(\widehat{v}_{c}\right)$ is the sliding surface, and $\rho$ is the control gain.

In [76], SMC is used to control bending and torsional vibration of a six-story flexible structure. The controller takes into accounts two conditions as follows.

(1) Controller design considering only nonlinear control inputs: the dynamic system and the switching function are given by

$$
\begin{aligned}
\dot{x}(t) & =A x(t)+B u(t), \\
y(t) & =C x(t), \\
\sigma(t) & =S y(t),
\end{aligned}
$$

where $S$ is switching hyperplane. The controller has the following nonlinear form:

$$
u(t)=-K_{n t}(S C B)^{-1} \frac{\sigma(t)}{\|\sigma(t)\|}
$$

where $K_{n t}$ is the scalar coefficient, SCB is the multiplication factor of the matrices $S, C$, and $B$. 


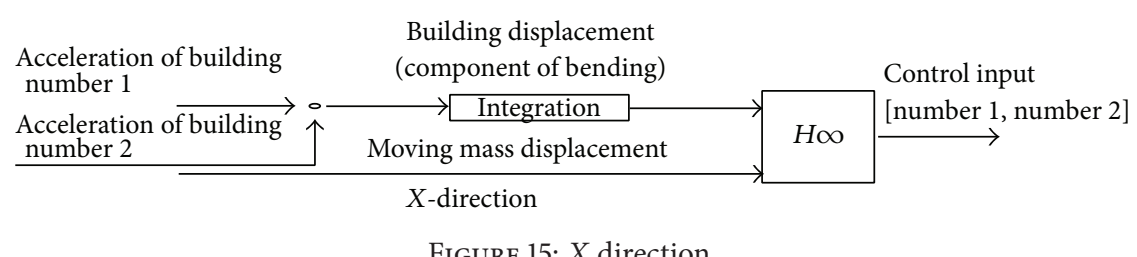

Figure 15: $X$ direction.
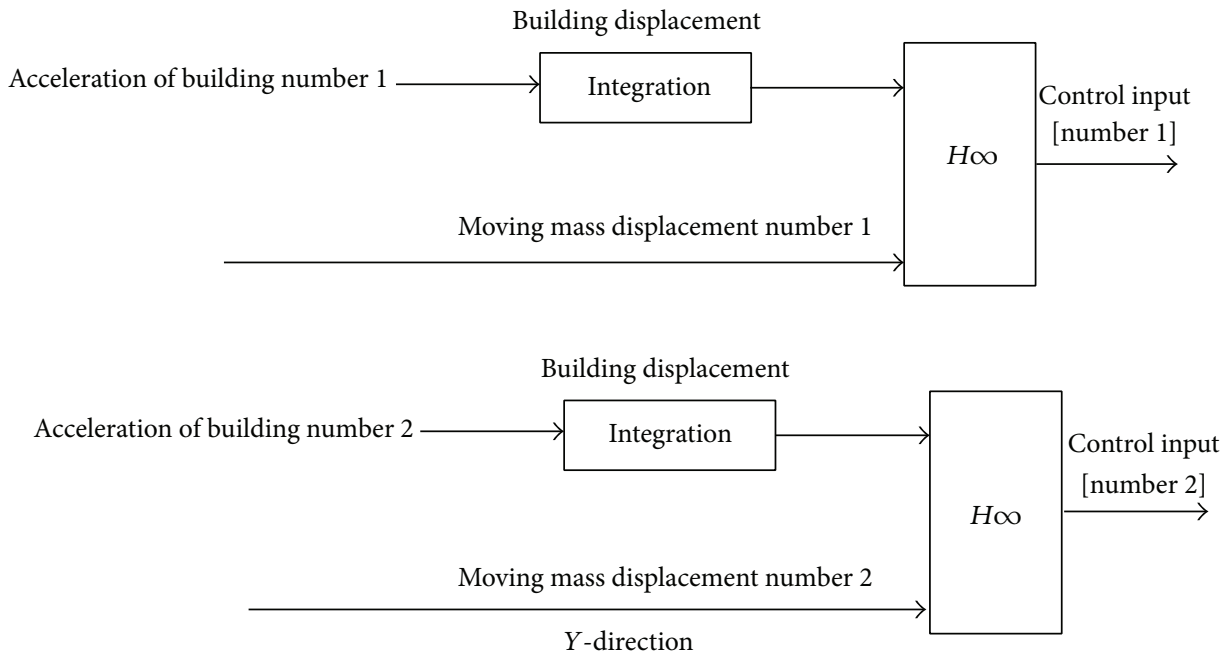

Figure 16: $Y$ direction.

(2) Controller design considering nonlinear and subequivalent control inputs: the controller has the following nonlinear form:

$$
u_{n t}(t)=-K_{n t}(S C B)^{-1} \frac{\sigma}{\|\sigma\|}
$$

Also,

$$
u=u_{t}+u_{n t}
$$

The inputs of sliding mode control are designed as the sumup of linear and nonlinear inputs. Subequivalent control inputs can be generated from the solo measured outputs as given in

$$
u_{t}=u_{\mathrm{eq}}=-k_{\mathrm{eq}} y,
$$

where $k_{\text {eq }}$ is the scalar equivalent. The important feature of SMC is robustness under the uncertainties and disturbances. Lyapunov stability theory is implemented to prove the system stability in [75].

4.4.2. Neural Network Based Structure Control. A neural network (NN) is characterized by (1) an area which consists of number of neurons along with their interconnections and layers and (2) its technique of evaluating the weights on the connections which is termed as learning algorithm. In [77], a neural network based emulator computes the response of a $2 \mathrm{D}$ frame structure involving 3-story building. The feedforward multilayer perceptron with the backpropagation algorithm is used in [54] for structure control. Reference [78] presents a wavelet neural network (WNN) based active nonlinear controller for 3D buildings subjected to seismic excitation in both $x$ and $y$ directions.

The combination of NN with the classical control theory yields better control results $[79,80]$. The hybrid intelligent control algorithm applied to semiactive control of the magnetorheological (MR) damper is presented in [74]. It is subjected to bidirectional seismic wave. The training data for structure usually need to be normalized into $[0,1]$

$$
\bar{N}_{i}=\frac{2\left(N_{i}-N_{i, \text { min }}\right)}{N_{i, \max }-N_{i, \text { min }}}-1,
$$

where $N_{i}$ is the input component and its domain is $\left(N_{i \text {,min }}, N_{i \text {,max }}\right)$. Reference [81] presents a direct adaptive neural controller subjected to bidirectional earthquake inputs. Both the system parameters and the nonlinear estimation of force have uncertainties, which can be canceled by the adaptive controller. The control law is

$$
\begin{aligned}
& F_{c}^{*}(k)=\bar{G}\left(z(k-1), \ldots, z\left(k-n_{1}\right), A_{g}(k), \ldots,\right. \\
& \left.A_{g}\left(k-n_{1}\right)\right)=\bar{G}(V),
\end{aligned}
$$

where $n_{1} \geq n, \bar{G}$ is the mapping function, and $F_{c}^{*}(k)$ is the desired control force. NN is used to model $\bar{G}$. References [82, 83] use $\mathrm{NN}$ for the structural reliability analysis. Reference [84] proposes a NN based prediction scheme for the dynamic behavior of structural systems under 
multiple seismic excitations. The NN prediction includes two different ways: (1) a nonadaptive scheme that uses multiple accelerometers in training $\mathrm{NN}$ and utilizes for the prediction of the structural seismic response; (2) an adaptive that scheme uses multiple accelerometers in the training.

4.4.3. Fuzzy Control. Linguistic criteria are an effective feature of fuzzy control rules that can be easily modified and understood clearly [85]. The application of fuzzy logic in structural control has been studied by [17]. Reference [47] proposes a fuzzy logic controller with multipurpose optimal design to drive hybrid mass damper (HMD) for the response control of the torsionally coupled seismically excited buildings. HMD system consists of four HMDs arranged in such a way that this system can control the torsional mode of vibration effectively in addition to the texture modes of vibration. The design of the fuzzy logic controller (flC) is based on the selection procedure that includes five membership functions for each of input variable and seven membership functions for the output variable. The input and output variables includes acceleration and velocity in $x, y$, and $\theta$ directions and control command $u_{c}$, respectively.

In their study, bell shaped membership functions have been used and are represented by

$$
\mu_{x}=\frac{1}{1+|(x-c) / a|^{2 b}},
$$

where $a$ is the half-width of the membership function at 0.5 membership grade, $b$ is the membership function slope, and $c$ is the central position of the membership function.

The minimization of structural torsion responses using semiactive dampers has been presented by [86]. In their investigation, the MR damper is employed for the real time control of the response of structures under seismic excitations. The methodology of fuzzy modeling of MR dampers has been shown in [87]. Reference [88] presents a numerical study to show the effectiveness of a supervisory fuzzy logic controller for seismic response control of an eight-story base isolated structure effected by translation-torsional motion. Reference [88] applies supervisory fuzzy controller to control two lower level fuzzy controllers. The weight is determined by

$$
V d=\frac{W_{N} V_{N}+W_{F} V_{F}}{W_{N}+W_{F}}
$$

where $W_{N}$ and $W_{F}$ are the weighting factors and $V_{N}$ and $V_{F}$ are the command voltages. Reference [89] shows that the dynamic fuzzy wavelet NN can precisely forecast structural displacements. Reference [78] had presented wavelet neural network (WNN) model based active nonlinear controller for the response control of 3D buildings subjected to seismic excitation in both $x$ and $y$ directions. The main aim is to control the torsional and lateral motions of 3D irregular structures. The structural responses are predicted using a dynamic fuzzy WNN which is a fuzzy wavelet neuroemulator. Estimation of future time steps is utterly necessary to control the structural responses effectively. This method is essential in determining the magnitude of the required control forces.
4.4.4. Structure Control with Genetic Algorithm. Holland, 1975, was the first to propose the general scheme of genetic algorithm (GA) and uses natural genetic theory to build an optimal search algorithm [90]. A GA can be divided into three parts [91]:

(1) Code and decode the variables into the strings form.

(2) Fit each solution string.

(3) Evaluate strings of the next generation by applying genetic operators.

The aim of the optimization problem is to evaluate the minimum of the performance index:

$$
\text { Adaptality }= \begin{cases}J_{\max }-J & \text { if } J<J_{\max } \\ 0 & \text { otherwise. }\end{cases}
$$

The applications of the GA method to structural control are published by various researchers. Reference [92] used GA to MR dampers in the reduction of translation-torsion coupled responses of an asymmetric structure. The experiment was carried out at the State Key Lab of Coastal and Offshore Engineering in Dalian University of Technology. The parameters of the multistate control strategy (MSC) which utilizes the velocity response as the state-switch parameter are optimized by genetic algorithm (GA) method. This MSC is developed in the intention to control torsional seismic response of an asymmetric structure. In their research, also the threshold vector of the MR damper is optimized using genetic algorithm. The parameters from the velocity response and the threshold vector of the MR damper are optimized by the GA method. Reference [93] presents a new neurogenetic algorithm to evaluate the optimal control forces for active control of 3D building structures. It includes geometrical and material nonlinearities, coupling action between lateral and torsional motions, and actuator dynamics. In this case a floating-point GA was used. The methodology used can be categorized as follows: (i) representation of chromosomes, (ii) initial population, (iii) function related to fitness, (iv) selection function, (v) genetic operator, and (vi) termination scheme.

In the investigation mentioned, a nonuniform mutation operator is applied as the genetic operator to evaluate better solution for the new generation. It is expressed by

$$
F_{j}^{\prime}= \begin{cases}F_{j}+\left(F_{\max }-F_{j}\right) h(g), & \text { if } r_{1} \geq 0.5 \\ F_{j} & \text { otherwise, }\end{cases}
$$

where $j=1,2, \ldots, N_{p}, F_{j}$ is $j$ th variable value in the chromosomes related to current population, $F_{j}^{\prime}$ is improved value of the same variable related to the new generation, and $h(g)$ is robability function of mutation.

The study results suggest that the new control technique efficiently reduces the response of two irregular 3D building structures under seismic inputs including structures with plan and irregular elevation. The study results suggest that the new control technique efficiently reduces the response 
of two irregular 3D building structures under seismic inputs including structures with plan and irregular elevation. Reference [78] develops a new nonlinear control model for the active control of a 3D building structure. The optimal control forces are computed with the floating-point GA. GA can help to decide the positions of the control devices [45]. The coupled torsional-lateral response is attenuated by a semiactive control under bidirectional seismic input. Reference [94] gives a technique of reducing the seismic effects of the spatial structures by the installation of magnetorheological (MR) dampers. It uses small populations to solve the optimization problem embedded in the semiactive control. GA is used to optimize dampers passive parameters and controller gain in [95].

The concept of absorber system with multiobjective optimal design for torsionally coupled earthquake excited structures is presented by [47]. It uses a multiobjective version of GA to extract the design parameters of absorber system. The two branch tournament genetic algorithm as mentioned by [96] extend two-branch tournament GA to three-branch tournament GA and applies to the multiple bjective optimization of the TMD system.

\section{Conclusions and Remarks}

In this review, the modeling and structural control techniques of building structures subjected to bidirectional earthquake are considered. The main difference with normal structure controllers is the lateral-torsional coupled response. We discuss recent new techniques, methodology, and concepts in this areas. We focus all important results in last two decades in the field of structural engineering with respect to the bidirectional earthquakes.

From the analysis of the above paper, we have the following important observations:

(1) Most of existing reviews only consider the structure control under unidirectional seismic wave. This review explores the effects of bidirectional seismic waves, which are normal for the real earthquake.

(2) Real buildings are generally asymmetric in nature to some extent. These criteria induce lateral and torsional vibrations in combination.

(3) The reduction of translational and torsional response of structures often involves the usage of multiple dampers [97].

(4) Hybrid control devices are more popular due to their abilities for the seismic vibration along 3-DoF. The authors $[47,98]$ in their investigation have used hybrid mass damper to control vibration along 3-DoF. The proposed HMD system consists of four HMDs arranged in such a way that this system can control the torsional mode of vibration effectively in addition to the flexure modes of vibration.

(5) Few papers use sliding mode control to reduce translation-torsion coupled vibration with bidirectional seismic inputs.
(6) Finding placement of control devices is a challenging task especially for coupled lateral and torsional responses.

(7) In case of building structures subjected to multiple excitations, the use of online identification technique is better.

(8) The intelligent control is favored for the structural control, because it does not require system information.

\section{Conflict of Interests}

The authors declare that there is no conflict of interests regarding the publication of this paper.

\section{References}

[1] N. R. Fisco and H. Adeli, "Smart structures: part I-active and semi-active control," Scientia Iranica, vol. 18, no. 3, pp. 275-284, 2011.

[2] N. R. Fisco and H. Adeli, "Smart structures: part II-hybrid control systems and control strategies," Scientia Iranica, vol. 18, no. 3, pp. 285-295, 2011.

[3] J. T. P. Yao, "Concept of structural control," Journal of the Structural Division, vol. 98, no. 7, pp. 1567-1574, 1972.

[4] G. W. Housner, L. A. Bergman, T. K. Caughey et al., "Structural control: past, present, and future," Journal of Engineering Mechanics, vol. 123, no. 9, pp. 897-971, 1997.

[5] R. J. McNamara, “Tuned mass dampers for buildings," Journal of the Structural Division, vol. 103, no. 9, pp. 1785-1798, 1977.

[6] B. Donaldson, Introduction to Structural Dynamics, Cambridge University Press, Cambridge, UK, 2006.

[7] F. Yi and S. J. Dyke, "Structural control systems: performance assessment," in Proceedings of the American Control Conference, vol. 1, pp. 14-18, IEEE, Chicago, Ill, USA, September 2000.

[8] E. Cruz and S. Cominetti, "Three-dimensional buildings subjected to bi-directional earthquakes. Validity of analysis considering unidirectional earthquakes," in Proceedings of the 12th World Conference on Earthquake Engineering, Auckland, New Zealand, January-Friday 2000.

[9] J.-S. Heo, S.-K. Lee, E. Park et al., "Performance test of a tuned liquid mass damper for reducing bidirectional responses of building structures," The Structural Design of Tall and Special Buildings, vol. 18, no. 7, pp. 789-805, 2009.

[10] J. Zhang, K. Zeng, and J. Jiang, "An optimal design of bidirectional TMD for three dimensional structure," in Computational Structural Engineering, pp. 935-941, Springer, Dordrecht, The Netherlands, 2009.

[11] J.-L. Lin and K.-C. Tsai, "Seismic analysis of two-way asymmetric building systems under bi-directional seismic ground motions," Earthquake Engineering and Structural Dynamics, vol. 37, no. 2, pp. 305-328, 2008.

[12] A. Forrai, S. Hashimoto, H. Funato, and K. Kamiyama, "Structural control technology: system identification and control of flexible structures," Computing and Control Engineering Journal, vol. 12, no. 6, pp. 257-262, 2001.

[13] J. Zhang and P. N. Roschke, "Active control of a tall structure excited by wind," Journal of Wind Engineering and Industrial Aerodynamics, vol. 83, no. 1-3, pp. 209-223, 1999. 
[14] W. K. Tso and T. J. Zhu, "Design of torsionally unbalanced structural systems based on code provisions I: ductility demand," Earthquake Engineering and Structural Dynamics, vol. 21, no. 7, pp. 609-627, 1992.

[15] J. C. Correnza, G. L. Hutchinson, and A. M. Chandler, "Effect of transverse load-resisting elements on inelastic earthquake response of eccentric-plan buildings," Earthquake Engineering \& Structural Dynamics, vol. 23, no. 1, pp. 75-89, 1994.

[16] W.-H. Wu, J.-F. Wang, and C.-C. Lin, "Systematic assessment of irregular building-soil interaction using efficient modal analysis," Earthquake Engineering \& Structural Dynamics, vol. 30, no. 4, pp. 573-594, 2001.

[17] K.-M. Choi, S.-W. Cho, D.-O. Kim, and I.-W. Lee, "Active control for seismic response reduction using modal-fuzzy approach," International Journal of Solids and Structures, vol. 42, no. 16-17, pp. 4779-4794, 2005.

[18] C.-C. Lin, C.-C. Chang, and J.-F. Wang, "Active control of irregular buildings considering soil-structure interaction effects," Soil Dynamics and Earthquake Engineering, vol. 30, no. 3, pp. 98-109, 2010.

[19] J. C. Anderson and F. Naeim, Basic Structural Dynamics, Wiley, Los Angeles, Calif, USA, 2012.

[20] A. C. Nerves and R. Krishnan, "Active control strategies for tall civil structures," in Proceedings of the International Conference on Industrial Electronics, Control, and Instrumentation, vol. 2, pp. 962-967, Orlando, Fla, USA, November 1995.

[21] A. K. Chopra, Dynamics of Structures, Prentice-Hall International Series, Prentice Hall, 2011.

[22] F. Y. Cheng, Matrix Analysis of Structural Dynamics: Applications and Earthquake Engineering, CRC Press, New York, NY, USA, 2000.

[23] G. C. Hart and K. Wong, Structural Dynamics for Structural Engineers, Wiley, 1999.

[24] B. Wu, J.-P. Ou, and T. T. Soong, "Optimal placement of energy dissipation devices for three-dimensional structures," Engineering Structures, vol. 19, no. 2, pp. 113-125, 1997.

[25] B. F. Spencer Jr. and S. Nagarajaiah, "State of the art of structural control," Journal of Structural Engineering, vol. 129, no. 7, pp. 845-856, 2003.

[26] T. T. Soong and B. F. Spencer Jr., "Supplemental energy dissipation: state-of-the-art and state-of-the-practice," Engineering Structures, vol. 24, no. 3, pp. 243-259, 2002.

[27] S. G. Luca, F. Chira, and V. O. Rosca, "Passive active and semi-active control systems in civil engineering," Constructil Arhitectura, vol. 3-4, pp. 23-32, 2005.

[28] T. T. Soong, Active Structural Control: Theory and Practice, Addison-Wesley, New York, NY, USA, 1999.

[29] M. C. Constantinou and M. D. Symans, "Seismic response of structures with supplemental damping," The Structural Design of Tall Buildings, vol. 2, no. 2, pp. 77-92, 1993.

[30] J. P. Hartog, Mechanical Vibrations, McGraw-Hill, New York, NY, USA, 1956.

[31] N. B. Desu, S. K. Deb, and A. Dutta, "Coupled tuned mass dampers for control of coupled vibrations in asymmetric buildings," Structural Control and Health Monitoring, vol. 13, no. 5, pp. 897-916, 2006.

[32] K. Xu and T. Igusa, "Dynamic characteristics of multiple substructures with closely spaced frequencies," Earthquake Engineering \& Structural Dynamics, vol. 21, no. 12, pp. 10591070, 1992.
[33] H.-N. Li and L.-S. Huo, "Seismic response reduction of eccentric structures using tuned liquid column damper (TLCD)," in Vibration Analysis and Control-New Trends and Development, InTech, 2011.

[34] M. J. Hochrainer, C. Adam, and F. Ziegler, "Application of tuned liquid column dampers for passive structural control," in Proceedings of the 7th International Congress on Sound and Vibration (ICSV'00), Garmisch-Partenkirchen, Germany, 2000.

[35] S. G. Liang, "Experiment study of torsionally structural vibration control using circular tuned liquid column dampers," Special Structures, vol. 13, no. 3, pp. 33-35, 1996.

[36] L. Huo and H. Li, "Torsionally coupled vibration control of eccentric buildings using liquid dampers," in Active and Passive Smart Structures and Integrated Systems, vol. 7288 of Proceedings of SPIE, 2009.

[37] C. Fu, "Application of torsional tuned liquid column gas damper for plan-asymmetric buildings," Structural Control and Health Monitoring, vol. 18, no. 5, pp. 492-509, 2011.

[38] T. K. Datta, "A state-of-the-art review on active control of structures," ISET Journal of Earthquake Technology, vol. 40, no. 1, pp. 1-17, 2003.

[39] R. Collins, B. Basu, and B. Broderick, "Control strategy using bang-bang and minimax principle for FRF with ATMDs," Engineering Structures, vol. 28, no. 3, pp. 349-356, 2006.

[40] J. C. H. Chang and T. T. Soong, "Structural control using active tuned mass damper," Journal of Engineering Mechanics, vol. 106, no. 6, pp. 1091-1098, 1980.

[41] C. Li, J. Li, and Y. Qu, "An optimum design methodology of active tuned mass damper for asymmetric structures," Mechanical Systems and Signal Processing, vol. 24, no. 3, pp. 746-765, 2010.

[42] A. Yanik, J. P. Pinelli, and H. Gutierrez, "Control of a threedimensionalstructure with magneto-rheological dampers," in Proceedings of the 11th International Conference on Vibration Problems, Z. Dimitrovova, J. Almeida, and R. Goncalves, Eds., Lisbon, Portugal, 2013.

[43] M. R. Jolly, J. W. Bender, and J. D. Carlson, "Properties and applications of commercial magnetorheological fluids," in Smart Structures and Materials 1998: Passive Damping and Isolation, vol. 3327 of Proceedings of SPIE, pp. 262-275, San Diego, Calif, USA, March 1998.

[44] J. Yang, J. B. Li, and G. Lin, "A simple approach to integration of acceleration data for dynamic soil-structure interaction analysis," Soil Dynamics and Earthquake Engineering, vol. 26, no. 8, pp. 725-734, 2006.

[45] O. Yoshida and S. J. Dyke, "Response control of full-scale irregular buildings using magnetorheological dampers," Journal of Structural Engineering, vol. 131, no. 5, pp. 734-742, 2005.

[46] F. Yi, S. J. Dyke, J. M. Caicedo, and J. D. Carlson, "Experimental verification of multiinput seismic control strategies for smart dampers," Journal of Engineering Mechanics, vol. 127, no. 11, pp. 1152-1164, 2001.

[47] A. S. Ahlawat and A. Ramaswamy, "Multiobjective optimal FLC driven hybrid mass damper system for torsionally coupled, seismically excited structures," Earthquake Engineering \& Structural Dynamics, vol. 31, no. 12, pp. 2121-2139, 2002.

[48] H. Kim and H. Adeli, "Hybrid control of irregular steel highrise building structures under seismic excitations," International Journal for Numerical Methods in Engineering, vol. 63, no. 12, pp. 1757-1774, 2005. 
[49] J. M. Angeles-Cervantes and L. Alvarez-Icaza, "3D Identification of buildings seismically excited," in Proceedings of the 16th IFAC World Congress, vol. 16, Prague, Czech Republic, 2005.

[50] V. Gattulli, M. Lepidi, and F. Potenza, "Seismic protection of frame structures via semi-active control: modeling and implementation issues," Earthquake Engineering and Engineering Vibration, vol. 8, no. 4, pp. 627-645, 2009.

[51] J.-L. Lin, K.-C. Tsai, and Y.-J. Yu, "Bi-directional coupled tuned mass dampers for the seismic response control of twoway asymmetric-plan buildings," Earthquake Engineering \& Structural Dynamics, vol. 40, no. 6, pp. 675-690, 2011.

[52] B. Zhao and H. Gao, "Torsional vibration control of high-rise building with large local space by using tuned mass damper," Advanced Materials Research, vol. 446-449, pp. 3066-3071, 2012.

[53] M. P. Singh, S. Singh, and L. M. Moreschi, "Tuned mass dampers for response control of torsional buildings," Earthquake Engineering and Structural Dynamics, vol. 31, no. 4, pp. 749-769, 2002.

[54] Y. Tang, "Active control of SDF systems using artificial neural networks," Computers and Structures, vol. 60, no. 5, pp. 695-703, 1996.

[55] R. Alkhatib and M. F. Golnaraghi, "Active structural vibration control: a review," The Shock and Vibration Digest, vol. 35, no. 5, pp. 367-383, 2003.

[56] M. D. Symans and M. C. Constantinou, "Semi-active control of earthquake induced vibration," in Proceedings of the 11th World Conference on Earthquake Engineering, Acapulco, Mexico, June 1996.

[57] A. K. Agrawal and J. N. Yang, "Compensation of time-delay for control of civil engineering structures," Earthquake Engineering \& Structural Dynamics, vol. 29, no. 1, pp. 37-62, 2000.

[58] F. Amini and M. R. Tavassoli, "Optimal structural active control force, number and placement of controllers," Engineering Structures, vol. 27, no. 9, pp. 1306-1316, 2005.

[59] O. Ibidapo-Obe, "Optimal actuators placements for the active control of flexible structures," Journal of Mathematical Analysis and Applications, vol. 105, no. 1, pp. 12-25, 1985.

[60] W. Gawronski, "Actuator and sensor placement for structural testing and control," Journal of Sound and Vibration, vol. 208, no. 1, pp. 101-109, 1997.

[61] J. M. Angeles-Cervantes and L. Alvarez-Icaza, "3D identification of seismically excited buildings with sensors arbitrarily placed," in Proceedings of the American Control Conference, pp. 3807-3812, Minneapolis, Minn, USA, June 2006.

[62] S. M. Nigdeli and M. H. Boduroglu, "Active tendon control of torsionally irregular structures under near-fault ground motion excitation," Computer-Aided Civil and Infrastructure Engineering, vol. 28, no. 9, pp. 718-736, 2013.

[63] R. Guclu, "Sliding mode and PID control of a structural system against earthquake," Mathematical and Computer Modelling, vol. 44, no. 1-2, pp. 210-217, 2006.

[64] I. J. Vial, J. C. de la Llera, J. L. Almazán, and V. Ceballos, “Torsional balance of plan-asymmetric structures with frictional dampers: experimental results," Earthquake Engineering and Structural Dynamics, vol. 35, no. 15, pp. 1875-1898, 2006.

[65] O. Yoshida, S. J. Dyke, L. M. Giacosa, and K. Z. Truman, "Experimental verification of torsional response control of asymmetric buildings using MR dampers," Earthquake Engineering and Structural Dynamics, vol. 32, no. 13, pp. 2085-2105, 2003.
[66] C.-M. Chang, B. F. Spencer Jr., and P. Shi, "Multiaxial active isolation for seismic protection of buildings," Structural Control and Health Monitoring, vol. 21, no. 4, pp. 484-502, 2014.

[67] H. Adeli and A. Saleh, "Optimal control of adaptive/smart bridge structures," Journal of Structural Engineering, vol. 123, no. 2, pp. 218-226, 1997.

[68] R. E. Christenson, B. F. Spencer Jr., N. Hori, and K. Seto, "Coupled building control using acceleration feedback," ComputerAided Civil and Infrastructure Engineering, vol. 18, no. 1, pp. 418, 2003.

[69] Y. Du and Z. Lin, "Sequential optimal control for serially connected isolated structures subject to two-directional horizontal earthquake," in Proceedings of the 8th IEEE International Conference on Control and Automation (ICCA '10), pp. 15081511, Xiamen, China, June 2010.

[70] N. K. Chandiramani and G. B. Motra, "Lateral-torsional response control of MR damper connected buildings," in Proceedings of the International Mechanical Engineering Congress and Exposition (IMECE '13), vol. 4, ASME, San Diego, Calif, USA, November 2013.

[71] R. Zemp, J. C. De La Llera, and J. L. Almazán, “Tall building vibration control using a TM-MR damper assembly," Earthquake Engineering and Structural Dynamics, vol. 40, no. 3, pp. 339-354, 2011.

[72] V. I. Utkin, Sliding Modes in Control and Optimization, Springer, Berlin, Germany, 1992.

[73] T. Fujinami, Y. Saito, M. Morishita, Y. Koike, and K. Tanida, "A hybrid mass damper system controlled by $H^{\infty}$ control theory for reducing bending-torsion vibration of an actual building," Earthquake Engineering and Structural Dynamics, vol. 30, no. 11, pp. 1639-1653, 2001.

[74] Z. Li and S. Wang, "Robust optimal $\mathrm{H}_{\infty}$ control for irregular buildings with AMD via LMI approach," Nonlinear Analysis: Modelling and Control, vol. 19, no. 2, pp. 256-271, 2014.

[75] T. H. Nguyen, N. M. Kwok, Q. P. Ha, J. Li, and B. Samali, "Adaptive sliding mode control for civil structures using magnetorheological dampers," in Proceedings of the 23rd International Symposium on Automation and Robotics in Construction, pp. 636-641, Tokyo, Japan, 2006.

[76] K. Iwamoto, Y. Koike, K. Nonami, K. Tanida, and I. Iwasaki, "Output feedback sliding mode control for bending and torsional vibration control of 6-story flexible structure," JSME International Journal, Series C: Mechanical Systems, Machine Elements and Manufacturing, vol. 45, no. 1, pp. 150-158, 2002.

[77] J. Ghaboussi and A. Joghataie, "Active control of structures using neural networks," Journal of Engineering Mechanics, vol. 121, no. 4, pp. 555-567, 1995.

[78] X. Jiang and H. Adeli, "Pseudospectra, MUSIC, and dynamic wavelet neural network for damage detection of highrise buildings," International Journal for Numerical Methods in Engineering, vol. 71, no. 5, pp. 606-629, 2007.

[79] K. Bani-Hani and J. Ghaboussi, "Nonlinear structural control using neural networks," Journal of Engineering Mechanics, vol. 124, no. 3, pp. 319-327, 1998.

[80] J.-T. Kim, H.-J. Jung, and I.-W. Lee, "Optimal structural control using neural networks," Journal of Engineering Mechanics, vol. 126, no. 2, pp. 201-205, 2000.

[81] S. Suresh, S. Narasimhan, and S. Nagarajaiah, "Direct adaptive neural controller for the active control of earthquakeexcited nonlinear base-isolated buildings," Structural Control and Health Monitoring, vol. 19, no. 3, pp. 370-384, 2012. 
[82] N. D. Lagaros, V. Plevris, and M. Papadrakakis, "Neurocomputing strategies for solving reliability-robust design optimization problems," Engineering Computations, vol. 27, no. 7, pp. 819-840, 2010.

[83] N. D. Lagaros and M. Fragiadakis, "Fragility assessment of steel frames using neural networks," Earthquake Spectra, vol. 23, no. 4, pp. 735-752, 2007.

[84] N. D. Lagaros and M. Papadrakakis, "Neural network based prediction schemes of the non-linear seismic response of 3D buildings," Advances in Engineering Software, vol. 44, no. 1, pp. 92-115, 2012.

[85] L. A. Zadeh, "Fuzzy sets," Information and Control, vol. 8, no. 3, pp. 338-353, 1965.

[86] D. A. Shook, P. N. Roschke, P.-Y. Lin, and C.-H. Loh, "Semiactive control of a torsionally-responsive structure," Engineering Structures, vol. 31, no. 1, pp. 57-68, 2009.

[87] D. A. Shook, P. N. Roschke, P.-Y. Lin, and C.-H. Loh, "GAoptimized fuzzy logic control of a large-scale building for seismic loads," Engineering Structures, vol. 30, no. 2, pp. 436449, 2008.

[88] D. G. Reigles and M. D. Symans, "Supervisory fuzzy control of a base-isolated benchmark building utilizing a neuro-fuzzy model of controllable fluid viscous dampers," Structural Control and Health Monitoring, vol. 13, no. 2-3, pp. 724-747, 2006.

[89] H. Adeli and X. Jiang, "Dynamic fuzzy wavelet neural network model for structural system identification," Journal of Structural Engineering, vol. 132, no. 1, pp. 102-111, 2006.

[90] J. H. Holland, Adaptation in Natural and Artificial Systems, MIT Press, 1975.

[91] C. Camp, S. Pezeshk, and G. Cao, "Optimized design of twodimensional structures using a genetic algorithm," Journal of Structural Engineering, vol. 124, no. 5, pp. 551-559, 1998.

[92] H.-N. Li and X.-L. Li, "Experiment and analysis of torsional seismic responses for asymmetric structures with semi-active control by MR dampers," Smart Materials and Structures, vol. 18, no. 7, Article ID 075007, 2009.

[93] X. Jiang and H. Adeli, "Neuro-genetic algorithm for non-linear active control of structures," International Journal for Numerical Methods in Engineering, vol. 75, no. 7, pp. 770-786, 2008.

[94] H.-N. Li, Z.-G. Chang, G.-B. Song, and D.-S. Li, "Studies on structural vibration control with MR dampers using $\mu \mathrm{GA}$," in Proceedings of the American Control Conference (AAC '04), vol. 6, pp. 5478-5482, Boston, Mass, USA, July 2004.

[95] Y. Arfiadi and M. N. S. Hadi, "Passive and active control of three-dimensional buildings," Earthquake Engineering and Structural Dynamics, vol. 29, no. 3, pp. 377-396, 2000.

[96] W. A. Crossley, A. M. Cook, D. W. Fanjoy, and V. B. Venkayya, "Using the two branch tournament genetic algorithm for multiobjective design," AIAA Journal, vol. 37, no. 2, pp. 261-267, 1999.

[97] H.-N. Li and L.-S. Huo, "Optimal design of liquid dampers for torsionally coupled vibration of structures," Intelligent Control and Automation, vol. 5, pp. 4535-4538, 2004.

[98] L.-S. Fur, H. T. Y. Yang, and S. Ankireddi, "Vibration control of tall buildings under seismic and wind loads," Journal of Structural Engineering, vol. 122, no. 8, pp. 948-957, 1996. 


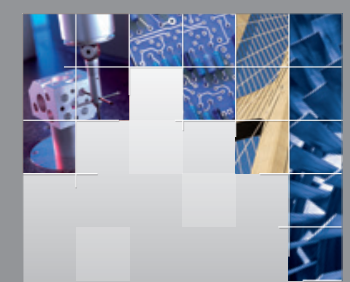

\section{Enfincering}
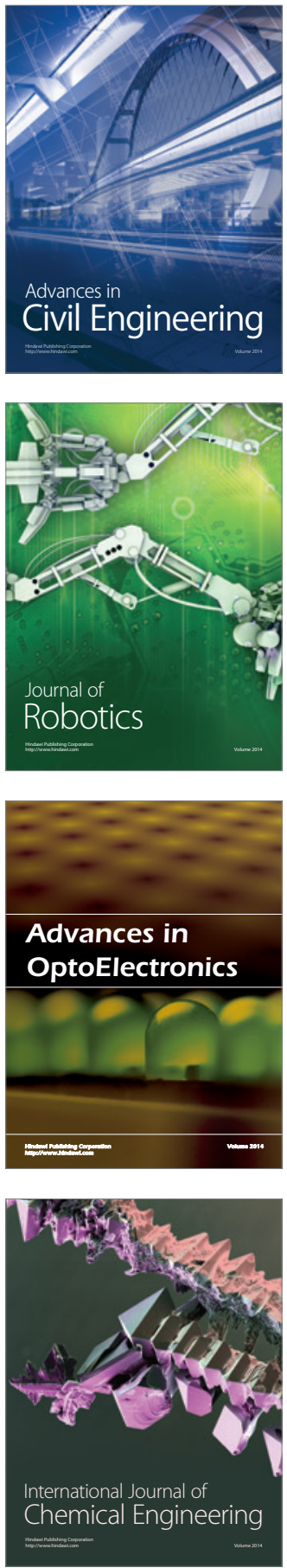

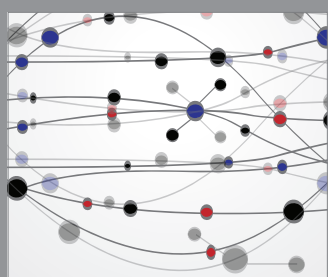

The Scientific World Journal

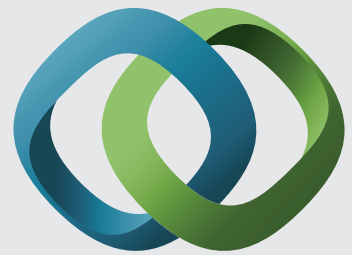

\section{Hindawi}

Submit your manuscripts at

http://www.hindawi.com
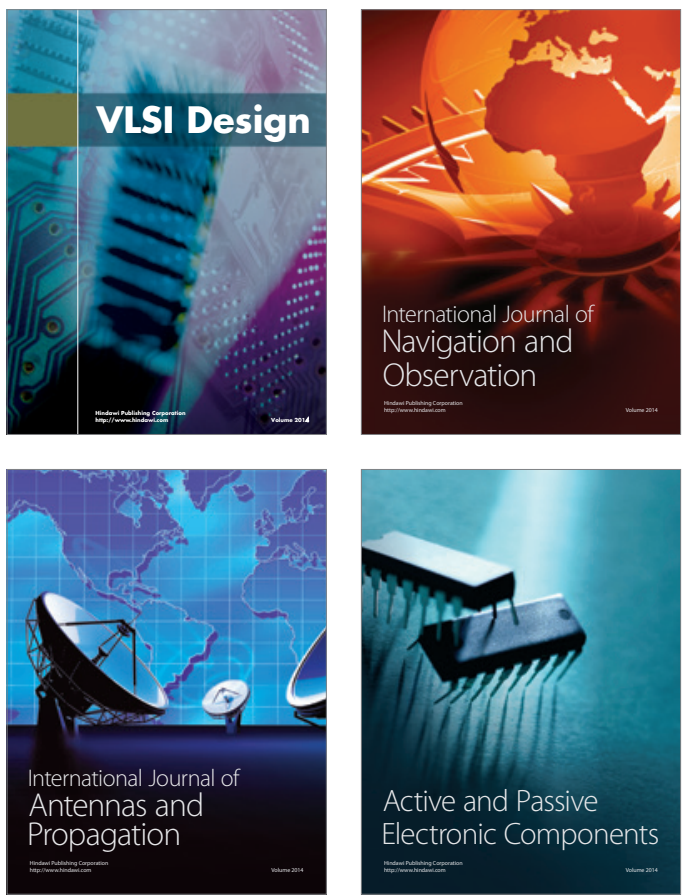
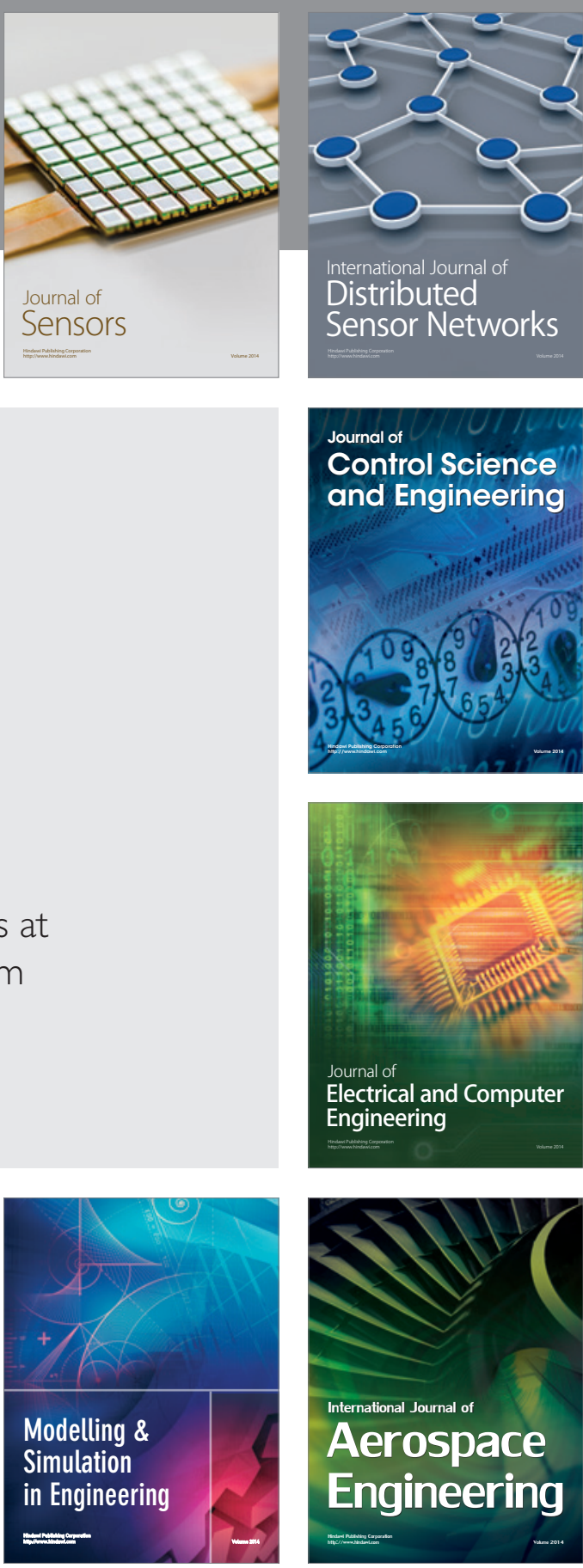

International Journal of

Distributed

Sensor Networks

Journal of

Control Science

and Engineering
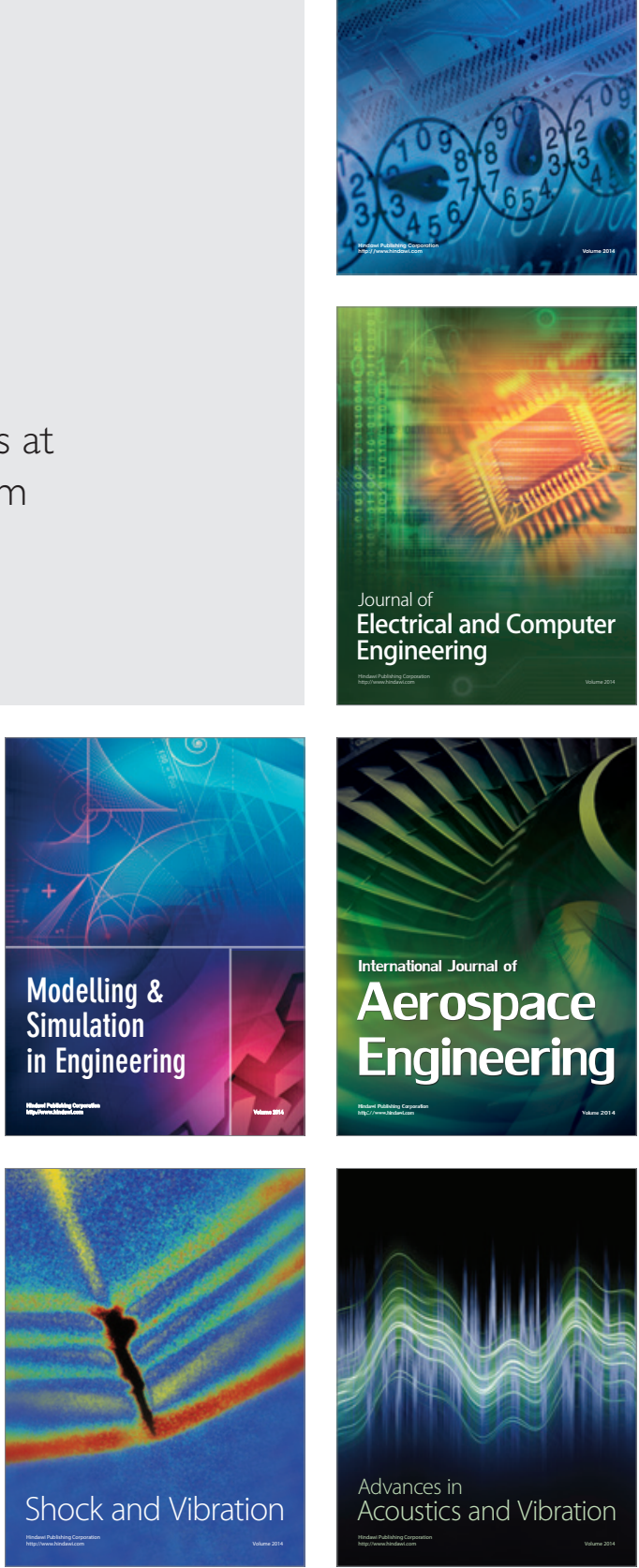